Jan Philipp Schägner, Joachim Maes, Luke Brander, Maria Luisa Paracchini, Volkmar Hartje, Gregoire Dubois

\title{
Monitoring recreation across European nature areas: A geo-database of visitor counts, a review of literature and a call for a visitor counting reporting standard
}

Journal article | Accepted manuscript (Postprint)

This version is available at https://doi.org/10.14279/depositonce-8671

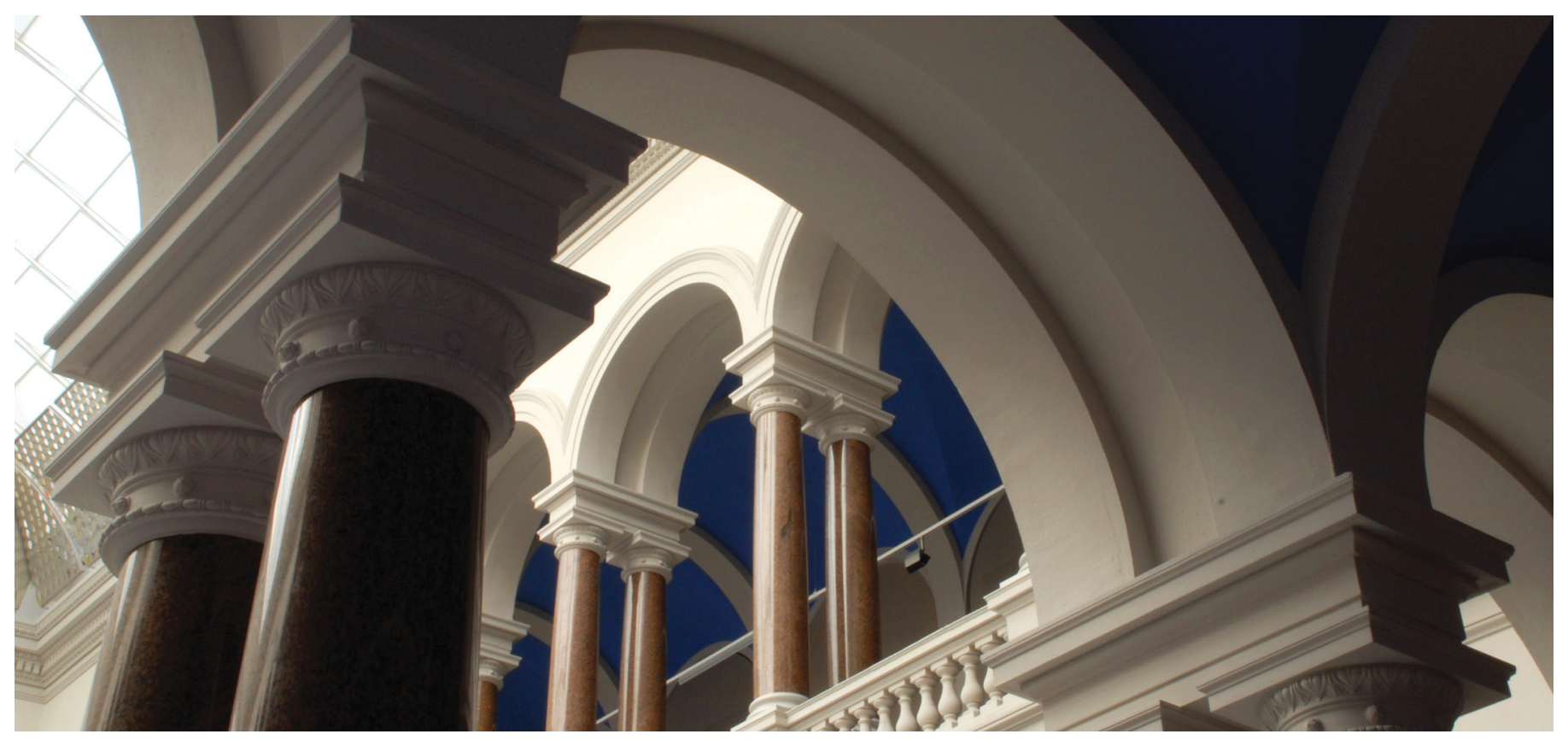

Schägner, J. P., Maes, J., Brander, L., Paracchini, M.-L., Hartje, V., \& Dubois, G. (2017). Monitoring recreation across European nature areas: A geo-database of visitor counts, a review of literature and a call for a visitor counting reporting standard. Journal of Outdoor Recreation and Tourism, 18, 44-55. https://doi.org/10.1016/j.jort.2017.02.004 


\title{
Monitoring Recreation Across European Nature Areas: A Geo-database of Visitor Counts, a Review of Literature and a Call for a Visitor Counting Reporting Standard
}

Jan Philipp Schägnera; Joachim Maes ${ }^{\mathrm{a}}$; Luke Brander ${ }^{\mathrm{b}}$; Maria Luisa Paracchini ${ }^{\mathrm{a}}$; Volkmar Hartje ${ }^{\mathrm{c}}$; Gregoire Dubois $^{\mathrm{a}}$

Key words:

Visitor monitoring

Recreation

Literature review

Reporting standards

Meta-analysis

Database

\begin{abstract}
:
Nature recreation and tourism is a substantial ecosystem service of Europe's countryside that has a substantial economic value and contributes considerably to income and employment of local communities. Highlighting the recreational value and economic contribution of nature areas can be used as a strong argument for the funding of protected and recreational areas. The total number of recreational visits of a nature area has been recognised as a major determinant of its economic recreational value and its contribution to local economies. This paper presents an international geodatabase on recreational visitor numbers to non-urban ecosystems, containing 1,267 observations at 518 separate case study areas throughout Europe. The monitored sites are described by their centroid coordinates and shape files displaying the exact extension of the sites. Therefore, the database illustrates the spatial distribution of visitor counting throughout Europe and can be used for secondary research, such as for validation of spatially explicit recreational ecosystem service models and for identifying relevant drivers of recreational ecosystem services. To develop the database, we review visitor monitoring literature throughout Europe and give an overview of such activities with special attention to visitor counting. We identify one major shortcoming in available literature, which relates to the presentation, study area definition and methodological reporting of conducted visitor counting studies. Insufficient reporting hampers the identification of the study area, the comparability of different studies and the evaluation of the studies' quality. Based on our findings, we propose a standardised reporting template for visitor counting studies and advanced data sharing for recreational visitor data. Researchers and institutions are invited to report on their visitor counting studies via our web interface at rris.biopama.org/visitor-reporting to contribute to a global visitor database that will be shared via the ESP Visualisation tool (http://esp-mapping.net).
\end{abstract}

${ }^{a}$ European Commission, Joint Research Centre, Ispra, Italy; ${ }^{b}$ Vrije Universiteit, Amsterdam, The Netherlands; 'Technical University Berlin, Germany

Published in: 2016. Journal of Outdoor Recreation and Tourism, 18 (June): 44-55. doi.org/10.1016/i.jort.2017.02.004 


\section{Introduction}

Recreation is a major ecosystem service provided by non-urban ecosystems that is of substantial economic importance. All across Europe, national parks are estimated to receive more than 2 billion recreational visits per year, which accounts for an economic recreational value of about $€ 14.5$ billion (Schägner et al. 2016a). Globally, protected areas are considered to provide an economic recreational value of \$US 250 billion annually through receiving 8 billion recreational visitors, who spend \$US 600 billion within the destination country (Balmford et al. 2015a). The economic value of nature recreation and its contribution to local economies can be used as a major argument for funding nature conservation and recreational facilities (Eagles 2014).

The number of visits is the most important indicator of the economic value of recreational ecosystem services (Bateman et al. 2006b; Jones et al. 2003). Therefore, generating accurate and fine-resolution estimates of total annual recreational visits is of major importance in order to highlight the relevance and economic value of different ecosystems and landscape features for recreation as well as for the improvement of an efficient management of environmental capital. However, no aggregated data on visitor numbers to various nature areas exist on the international level. Eagles (2014) names visitor use and economic impact monitoring as two of the ten most important research priorities for recreational nature areas. By supplying site-specific visitor estimates, the importance and value of different ecosystems at different locations can be identified. As a result, resources can be allocated more efficiently and recreation sites can be defended against competing use. Site specific visitor estimates also have crucial relevance for designing the supply of recreational facilities, the protection of nature against overuse, avoiding visitor crowding and for the evaluation of site management strategies (Hadwen et al. 2007). Highlighting the importance of protected areas and ecosystems for recreational services has multiple effects on local and national policies in many different countries (Sievänen et al. 2008) and it is also required by the EU Biodiversity Strategy 2020 (Maes et al. 2013) and the Convention on Biological Diversity's (CBD) Strategic Plan (CBD 2010).

Nevertheless, within outdoor recreation research, studies focusing on the economic valuation of recreation are far more common than studies on estimating accurate visitor numbers, even though the number of visits is the most important indicator for the economic value of recreational ecosystem services. Furthermore, visitor numbers vary far more across recreational sites than the value per visit (Jones et al. 2003; Bateman et al. 2006). Several studies on the recreational value of nature undertake extensive valuation exercises, but are based on relatively poor visitor estimates. Several papers review studies on the economic valuation of recreation by conducting meta-analysis in order to identify the determinants of the studies' results (Bateman and Jones 2007; Rosenberger and Loomis 2000; Shresta et al. 2007; Zandersen and Tol 2009) or they present databases on the vast amount of studies, their results and methodologies used (McComb et al. 2006). For studies estimating the total recreational visitor numbers of certain sites, such information is relatively rare and less professionally organised. Bateman et al. (2006b) describe this disparity with "The Tale of Horse and Rabbit Stew", in which the cook spends most of his time preparing the rabbit for his king, even though it is the horse that makes the stew delicious. Schägner et al. (2016a) find that the spatial standard deviations of recreational visitor numbers are about 360 times larger than those of the economic value per visit. Cole (2006) states that visitor monitoring is "lost in the gulf between science and management". In recent years, the importance of accurate visitor estimates has become more and more recognised within the scientific community. The Tourism and Protected Areas Specialist (TAPAS) Group ${ }^{1}$, a joint initiative by

\footnotetext{
${ }^{1}$ For more information, see http://www.iucn.org/protected-areas/world-commission-protectedareas/wcpa/what-we-do/tourism-tapas.
} 
the International Union for Conservation of Nature (IUCN) and its World Commission on Protected Areas (WCPA), is currently acquiring funding for developing a global database on visitor numbers to IUCN Category II Protected Areas (national parks) (Spenceley 2016). A single conference session is dedicated to "Visitors count! - Count visitation! Tourism in protected areas ..." at IUCN World Conservation Congress 2016 (Engels 2016).

The importance of nature-based recreation is recognised by the EU Biodiversity Strategy to 2020. The physical and monetary mapping and assessment of ecosystem services including cultural services such as nature-based recreation is an essential part of this strategy under Action 5. Maes et al. (2016) describe an indicator framework that can be used to ensure that coherent assessment approaches are used throughout the European Union. The number of visitors is retained as the most important indicator to quantify nature-based recreation but they observe that no harmonised, spatially-explicit data for this indicator are available at EU level.

Data on long-term trends in recreational use for various sites is critical for the economic valuation of different recreational sites, in order to identify determinants of recreational use and to evaluate the effects of various management strategies. It is crucial to make the acquired data available to the international research community, such as by other data sharing tools in other disciplines (DEIMS 2015; Drakou et al. 2015; JRC 2015).

So far, only some publications review visitor monitoring studies. For example, Kajala et al. (2006) review trends of visitor monitoring in Scandinavian and Baltic countries. They highlight the importance of standardised approaches and methodologies across countries. In the follow-up report, Kajala et al. (2007) propose some standards for monitoring visitors in the Nordic and Baltic countries, but with a more general focus. Whereas Hornback and Eagles (1999) propose visitor monitoring standards for protected areas in an international context and focus more on the results of the conducted studies than on detailed reporting, Sievänen et al. (2008) and Sievänen et al. (2009) review recreational monitoring programs across Europe as well as recreational supply indicators, but with a focus on forests only. They also propose a harmonisation of visitor monitoring and counting programs.

We instead promote the application of a variety of approaches and methodologies in recreational visitor monitoring and counting in order to let the methods evolve and develop, but call for detailed and standardised reporting of results and applied methodologies. A wide variety of methods can be used to estimate the number of recreational visits including the evaluation of trail use, samples of personal counting, and automated remote controlled counting devices. Counting samples can be scaled up over time and space by different means of accounting for counting times, days, season and weather as well as counting locations. The emerging use of GPS tracking and social media may allow for new and more efficient ways of estimating visitor numbers for recreational sites (Brandenburg et al. 2008; Wood et al. 2013b). Each visitor counting method may have its specific advantages and disadvantages and the methodological choice may have a strong and systematic effect on the estimated visitor numbers and on the accuracy of the estimate. By comprehensive reporting of the methodological choice, statistical regression analysis by means of meta-analysis can identify these effects and thereby help to improve visitor counting methods and give insights into the drivers of recreational use. Thereby, detailed reporting allows comparing results of different methods, but also for visitor monitoring and counting methods to evolve and progress. A harmonisation of visitor monitoring and counting approaches would increase the comparability of different studies even more, but may require the application of methods that do not fit the site-specific circumstances and the purpose of the study. In addition, it may hamper methodological developments and innovations in visitor monitoring and counting. Quality and reporting standards for primary data collection have been repeatedly proposed in other disciplines in order to ease statistical assessments such as in environmental economic valuation (Eigenbrod et al. 2010a; Johnston and Rosenberger 2010; Loomis 
and Rosenberger 2006; Rosenberger and Phipps 2007; Rosenthal and DiMatteo 2001; Stanley et al. 2013) or species distribution sampling (EU BON and GBIF 2015; Walls et al. 2014).

Based on a broad review of visitor monitoring studies with special focus on visitor counting, we propose that recreational visitor counting should (1) receive far more attention in scientific literature and funding schemes and (2) apply a more scientific and professional approach towards presentation of the gathered results and knowledge as well as reporting of the used methodologies. Multiple visitor counting studies are characterised by rudimentary reporting that does neither allow identifying the study area without local knowledge nor the study's quality. Officially published visitor numbers that are based on rough guesses may overstate real numbers by up to 26 fold (Job et al. 2014; Mehnen 2005; Ruschkowski 2010).

Within this paper we contribute to the field of visitor monitoring and counting by: (1) presenting a harmonised, spatially-explicit geo-database at EU level containing 1,267 total annual visitor observations at 518 separate nature areas including their exact locations and extension, (2) giving a review on visitor monitoring activities throughout Europe with a specific focus on visitor counting, (3) proposing a methodological reporting standard template for visitor counting studies based on the findings of our literature review (see appendix of this chapter) and (4) inviting the community to submit their visitor counting data via an web interface to contribute to a global database at rris.biopama.org/visitor-reporting.

The visitor number database allows for identifying visitor counting studies across Europe and can be used to estimate the importance of different drivers of recreational use. Thereby it may help to design and manage attractive recreational areas. The review provides insights into the trends of visitor monitoring across Europe and gives guidance on future prospects in visitor monitoring and counting practice. The reporting standards may support the quality and transparency of future visitor counting studies by allowing for assessments of the quality of single visitor estimates and for drawing conclusions on future visitor counting practice. It may also support the use of study results for secondary research, such as reviewing methodological evolvements and to allow for conducting metaanalysis as done in other disciplines such as in recreational economic valuation (Rosenthal and DiMatteo 2001; Zandersen and Tol 2009).

This paper is organised as follows: Section 2 gives a brief description on why and how the data was collected. Section 3.1 gives some summary statistics on the database. Then, in section 3.2, we describe general trends in visitor counting across Europe, and in section 3.3 we identify shortcomings in recent methodological reporting in visitor monitoring and counting studies. Therefore, we propose a reporting standard for visitor counting studies. Section 4 discusses our main findings before we conclude in the final section.

\section{Methodology and Data}

The aim of the study was to build up a database of total annual recreational visitor numbers of nonurban ecosystems all across Europe, in order to highlight the importance and value of different ecosystems for nature recreation. The database serves as a basis for statistical regression analysis of the drivers of recreational use and the effects of different methodologies in order to identify what ecosystem characteristics and landscape features attract and deter recreational visitors. The modelling results are published in Schägner et al. (2016a) and Schägner et al. (2016b). Therefore, we collected recreational visitor estimates that relates to a clearly defined nature area within Europe and that represent the number of visitors for an entire year and also appear to be a reliable estimate. To collect data we conducted a vast review of visitor monitoring literature. Visitor monitoring consists of a variety of survey and counting exercises that are implemented in order to obtain systematic information about 
recreational visitors. Total annual visitor estimates are often produced as part of a visitor monitoring study (Kajala et al. 2007). To search for visitor data we consulted online search tools, using general search engines, such as Google scholar, web of science, science direct and Scopus. Furthermore, we contacted relevant stakeholders from governmental and non-governmental agencies as well as researchers and managers of national park administrations across Europe. Finally, relevant conference proceedings were scanned, particularly the International Conferences on Management and Monitoring Visitors in Recreational Areas (MMV). The primary search for data was conducted in English, searching for data published within international scientific publications. However, a large amount of data is published in grey literature, which is solely published in national languages. Therefore, we also conducted an extensive online search for data in German and more rudimentary searches in Italian, Spanish, French and Portuguese, the languages accessible to the authors of this study. All total annual visitor estimates were entered into an ArcGIS geo-database and combined with referenced bibliographic information, all available methodological information and a GIS-shape file that indicates the exact location and extension of the case study area. We obtained shape files for each case study area by extracting them from an existing database on protected areas (EEA 2013; IUCN and UNEP 2015), by contacting study authors or stake-holders or by manually drawing them from map images presented in the publication or on the internet. For further analysis, all area covered by water (either inland or ocean water) was erased from the shape files in order to derive shapes of the terrestrial area only. This was done in order to derive comparable estimates of visitors per hectare. Some case study areas, such as a lake or a marine protected area, consist of more than $90 \%$ of water cover and since visitors spend most of their time on land, water covered areas would be a distortion. The database allows extracting site-specific information of the different case study areas by using available GIS data, such as ecosystem characteristics, socio-demographic and climate data, without consulting single publications, stake-holders or collecting data on-site. While hunting for visitor data, we reviewed relevant visitor monitoring studies and activities in different European countries.

\section{Results}

\subsection{A Geo-database of Visitor Counts}

In total we found 1,267 total annual visitor observations of about 518 separate case study areas all across Europe, which estimate a total of about 400 million visits a year. By far, the most case study areas are located in the UK (170), but also in Italy (57) and the relatively small countries Denmark (57) and the Netherlands (50) show a large amount of case study areas. Surprisingly, only very few estimates for the large countries Germany (13) and France (5) were found. For the following EU countries we could not obtain any observation: Portugal, Bulgaria, Estonia, Lithonia, Greece, and Iceland and the small countries Luxembourg, Cypress and Malta, even though visitor monitoring activities take place in most countries. 


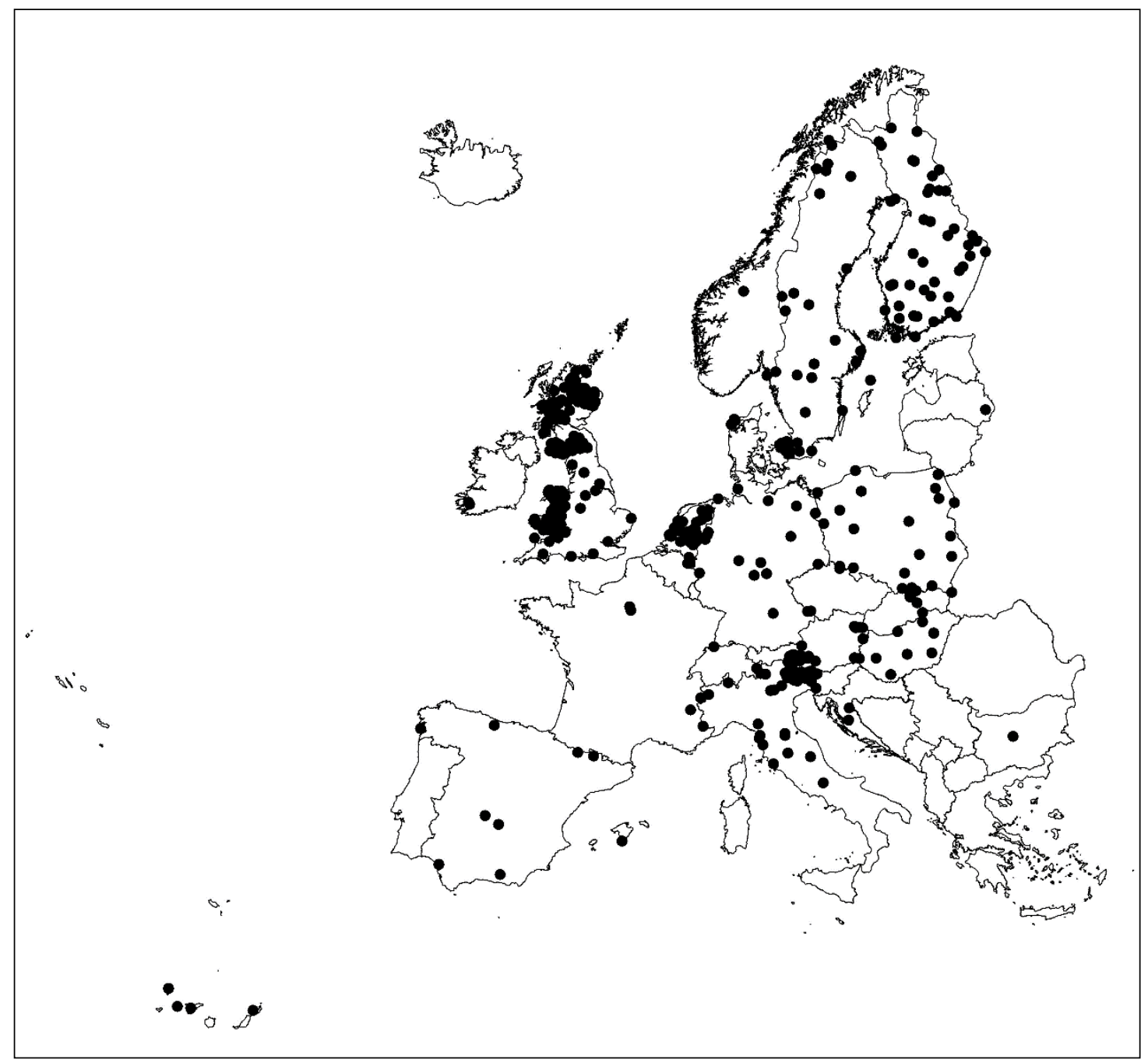

Figure 1: Location of total annual visitor observations across Europe. 
About $40 \%$ of all the observations represent visitor estimates of national parks or parts of national parks. Another $15 \%$ of case study areas are other types of protected areas ${ }^{2}$. We found a considerable amount of monitored sites not being protected at all only in four countries; 140 in the UK, 41 in Denmark, 27 in the Netherlands and 17 in Italy.

On average, each case study area receives about 760,000 visits a year. However, annual visits differ widely with regard to visitation rates per $\mathrm{km}^{2}$ and the case study area size. The overall average of the case study areas size is about $194 \mathrm{~km}^{2}$ big (excluding water cover), but ranges from only 1 hectare up to almost $9,000 \mathrm{~km}^{2}$. Country averages range from $13 \mathrm{~km}^{2}$ and $20 \mathrm{~km}^{2}$ in Denmark and the Netherlands up to $2,200 \mathrm{~km}^{2}$ in France. The average annual visits per terrestrial $\mathrm{km}^{2}$ are about 4,163, but differ widely. It ranges from three visits per $\mathrm{km}^{2}$ in large remote sites to up to 15.7 million in small visitor hot spot areas. There are stark differences between countries. For the Netherlands, the average is 36,600 visitors per $\mathrm{km}^{2}$ and for Finland only 213. Detailed statistical analysis of drivers explaining the differing visitation rates can be found in Schägner et al. (2016a) and Schägner et al. (2016b). Summary statistics on the gathered data are presented in Table 1. The entire database is presented in the SOM.

We were not able to obtain information on the methodology of the visitor counting studies for most of the case study areas in our database due to incomplete methodological reporting. As a result, it is impossible to apply a statistical assessment of the impacts of different visitor counting methodologies on the total annual visitor estimates. Some studies and databases list visitor numbers from multiple sites within tables without giving any reference to how this data was collected and how total annual visitor estimates are obtained. In many cases the information might be available in a language not accessible to the authors (BR 2008; BR 2012; GOBT 2007; GOBT 2009; GOBT 2010). A positive example of detailed visitor counting methodology reporting are the visitor monitoring studies of the UK Forestry Commission (TNS and FCS 2006b; TNS and FCS 2006a; TNS and FCS 2008; TNS and FCW 2005). On request, we could obtain detailed information including shapes of the study areas, precise counting locations, counting length and used devices as well as methodologies used to upscale the counted visits to the entire area and year. Many studies on single sites do have a different focus than finding total annual visitor estimates such as economic valuation of recreation (Cullinan et al. 2008a), evaluating the effect of crowding (Arnberger and Brandenburg 2007; Kalisch 2012) or the effects of dog walking (Jaarsma and Kooij 2010), but do include a total annual visitor estimate as a by-product. Other studies do collect all data required, but do not come up with a total annual visitor estimate, due to a different study focus (Andersen et al. 2014; Fredman et al. 2009).

\footnotetext{
${ }^{2}$ We classified each site as a protected area, if at least $50 \%$ of its area is classified as protected. For estimating the share of the total area classified as protected we used the intersect tool of ArcGIS 10.2, the World Database of Protected Areas and the Common Database of Designated Areas (EEA 2013; IUCN and UNEP 2015).
} 
Table 1: Summary of the database of annual visitor counts to sampled nature areas.

\begin{tabular}{|c|c|c|c|c|c|c|c|c|}
\hline Country & $\begin{array}{l}\text { Observa } \\
\text { tions }\end{array}$ & $\begin{array}{l}\text { National } \\
\text { parks }\end{array}$ & $\begin{array}{l}\text { Other } \\
\text { protecte } \\
\text { d areas }\end{array}$ & $\begin{array}{l}\text { Share } \\
\text { national } \\
\text { parks }\end{array}$ & $\begin{array}{l}\text { Share } \\
\text { protecte } \\
\text { d areas }\end{array}$ & $\begin{array}{l}\text { Total visitors } \\
\text { of sampled } \\
\text { sites }\end{array}$ & $\begin{array}{l}\text { Mean } \\
\text { visitors per } \\
\text { observatio } \\
\text { n }\end{array}$ & $\begin{array}{l}\text { Mean } \\
\text { visitors } \\
\text { per } \mathbf{k m}^{2}\end{array}$ \\
\hline Austria & 30 & 28 & 0 & $93 \%$ & $0 \%$ & $8,021,604$ & 267,387 & 1,370 \\
\hline Belgium & 2 & 0 & 1 & $0 \%$ & $50 \%$ & 136,835 & 68,418 & 289 \\
\hline Bulgaria & 1 & 1 & 0 & $100 \%$ & $0 \%$ & 15,000 & 15,000 & 21 \\
\hline Croatia & 2 & 2 & 0 & $100 \%$ & $0 \%$ & $1,056,726$ & 528,363 & 2,674 \\
\hline \multicolumn{9}{|l|}{ Czech } \\
\hline Republic & 3 & 3 & 0 & $100 \%$ & $0 \%$ & $7,460,771$ & $2,486,924$ & 5,648 \\
\hline Denmark & 57 & 5 & 11 & $9 \%$ & $19 \%$ & $16,097,268$ & 282,408 & 22,257 \\
\hline Finland & 46 & 39 & 6 & $85 \%$ & $13 \%$ & $2,337,254$ & 50,810 & 213 \\
\hline France & 5 & 3 & 0 & $60 \%$ & $0 \%$ & $30,566,216$ & $6,113,243$ & 2,750 \\
\hline Germany & 13 & 12 & 1 & $92 \%$ & $8 \%$ & $28,001,142$ & $2,153,934$ & 3,269 \\
\hline Hungary & 11 & 11 & 0 & $100 \%$ & $0 \%$ & $6,110,000$ & 555,455 & 1,310 \\
\hline Ireland & 2 & 1 & 0 & $50 \%$ & $0 \%$ & 78,504 & 39,252 & 672 \\
\hline Italy & 55 & 11 & 28 & $20 \%$ & $51 \%$ & $22,493,267$ & 408,968 & 1,769 \\
\hline Latvia & 1 & 1 & 0 & $100 \%$ & $0 \%$ & 55,667 & 55,667 & 93 \\
\hline Netherlands & 50 & 7 & 16 & $14 \%$ & $32 \%$ & $53,666,782$ & $1,073,336$ & 36,609 \\
\hline Norway & 1 & 1 & 0 & $100 \%$ & $0 \%$ & 30,000 & 30,000 & 19 \\
\hline Poland & 24 & 24 & 0 & $100 \%$ & $0 \%$ & $13,296,300$ & 554,013 & 3,983 \\
\hline Slovakia & 2 & 2 & 0 & $100 \%$ & $0 \%$ & $4,900,000$ & $2,450,000$ & 3,758 \\
\hline Slovenia & 1 & 1 & 0 & $100 \%$ & $0 \%$ & $2,000,000$ & $2,000,000$ & 2,386 \\
\hline Spain & 14 & 14 & 0 & $100 \%$ & $0 \%$ & $9,321,895$ & 665,850 & 2,742 \\
\hline Sweden & 27 & 26 & 1 & $96 \%$ & $4 \%$ & $2,256,369$ & 83,569 & 369 \\
\hline Switzerland & 1 & 1 & 0 & $100 \%$ & $0 \%$ & 165,000 & 165,000 & 1,001 \\
\hline UK & 170 & 16 & 14 & $9 \%$ & $8 \%$ & $184,132,506$ & $1,083,132$ & 7,638 \\
\hline sum & 518 & 209 & 78 & & & $392,200,000$ & 800,000 & \\
\hline mean & & & & $40 \%$ & $15 \%$ & & & 3,899 \\
\hline
\end{tabular}

\subsection{Visitor monitoring and Counting Activities in Europe}

The number of total annual visitor observations reported in this study represent an indicator of the visitor counting and monitoring activities in different European countries. For collecting the data, we reviewed visitor monitoring literature broadly, but with a special focus on studies estimating total 
annual visitor numbers. The results of this review are presented in the following section. However, we do not claim that the review is exhaustive and fully representative for visitor counting and monitoring in Europe for several reasons. First, we encountered difficulties as a lot of the primarily grey literature is published in national languages and is not accessible to the authors. Second, publication policies of visitor monitoring programs differ across countries and institutions. Asking stakeholders to supply data was characterised by varying success. Policies and helpfulness in supplying data differed across institutions and individuals and sometimes it was just a matter of luck to contact the right person at the right time, willing to help and having access the desired data. Finally, the primary purpose of this study was to construct a database on visitor counts and therefore we did not search and analyse visitor monitoring studies in depth that do not provide the desired data.

The visitor monitoring and counting activities differs not only in scope but also in focus across European countries. In many countries household surveys on the recreational activities are conducted. Such surveys offer valuable information, such as the number of trips, destinations, activities and recreational needs and attitudes, but are only rarely used for estimating site specific total visitor numbers. Often they allow for conclusions on the relative recreational use of different ecosystem types and/or regions, but not to estimate total numbers for a specific location. On-site surveys are also a common visitor monitoring practice, sometimes combined with visitor counting. However, in many cases such studies are not used to estimate total annual visitors, although the required information is collected. Some studies estimate visitor numbers only for some periods (peak days and seasons) or locations, but do not up-scale them to the entire area and year. A number of studies publish total annual visitor estimates for some sites, but because of incomplete reporting, the sites cannot be identified since either the extension or the locations of the sites are not distinct.

Applied methods for estimating total annual visitor numbers to recreational areas are manifold (see Table 2) and have diversified in recent years. Whereas most studies conduct on-site visitor counting to estimate total visitor numbers, some studies use on- and off-site surveys to estimate total visitor numbers. The application of survey data for recreational destination choice modelling has been applied several times in recent year (Sen et al. 2011a; Termansen et al. 2008; UK NEA 2011b). In the past, personal on-site counting, ticket sales or simple expert judgment based on indirect methods such as trail use etc. were most common, but new technical developments increase the options of visitor counting and estimation. Nowadays, automated remote controlled counting devices are widely used and offer great opportunities for extensive counting at relatively low costs. The application of drones, aerial images and high resolution satellite images are used to monitor species such as whales (Fretwell et al. 2014), elephants (McMahon et al. 2014) and penguins (Fretwell et al. 2012) as well as human crowds (Coghlan 2012). It may also be used for large scale visitor counting in recreational areas. Since the start of the digital and new media age, the vast amount of "big data" may open visitor estimation options that are currently hardly exploited and still to be explored. Mobile phone traffic and Wi-Fi tracking may be used to track visitors and their movements on sites, as what is done to estimate traffic jams (Stenovec 2015). On social media platforms, users share a vast amount of data that can also be used to estimate their recreational behaviour (Wood et al. 2013b). Search engine queries reveal the interest in certain locations. Online map surveys allow the researchers to generate surveys on recreational behaviour with increased spatial resolution at lower costs (Maptionnaire 2016). Smart phone app such as geocaching or sports activity trackers record movement patterns and the activity of recreational visitors (SDI4Apps 2016; Vítek 2012).

In the UK, where we found the most observations, but also in the Netherlands, Italy and Denmark, total annual visitor estimates of recreational areas are used as an indicator for the recreational importance and economic value of different recreational sites. This indicates a long term and widely accepted importance of expressing the value of recreational areas in economic terms that are often 
used to promote their conservation and compete for public funding. Also, many recreational valuation studies were found for these countries. In the UK, visitor monitoring is widely applied, not only for national parks and sites of recreational areas, but also for the general countryside (Cope et al. 2000; TNS and FCS 2006b). The Forestry Commission and as well Natural England provide a number of visitor monitoring studies, some publish only total annual visits, but others include general surveys on visitor needs, perception and behaviour (FC 2015; Kajala et al. 2007; NE 2014). Many of these studies focus on forest recreation. Visitor numbers are based on on-site counting (TNS and FCS 2006b; TNS and FCS 2006a; TNS and FCS 2008; TNS and FCW 2005) or on up-scaling of survey results (Jones et al. 2003; Morris and Doick 2009). Some data could be extracted from secondary studies, mainly environmental economic valuation studies (Bateman et al. 1998; Hill and Courtney 2006; Jones et al. 2003). Governmental databases present visitor numbers to a variety of visitor sites including indoor attractions such as museums and amusement parks, but also country parks and nature reserves. However, due to incomplete reporting, the quality of these estimates could not be assessed and in many cases it was difficult to define exact case study areas (VE 2014; VS 2013; VW 2014).

Most reports in Denmark and the Netherlands are published in national languages only and thus, we had difficulties in evaluating the visitor monitoring activities in detail. Multiple visitor estimates do show that they are vibrant. For Denmark we found indications of many total annual visitor estimates of mainly forest sites, resulting from a large scale of survey based methods and car traffic counts, some dating back to the 1970s (Jensen 1992; 2003; Jensen \& Guldager 2005; Kajala et al. 2006; Koch 1978; 1980; 1984; Sievänen et al. 2008; de Vries \& Veer 2007). However, we did succeed in accessing only some of these numbers. For the Netherlands, some publications list total visitor numbers for a variety of different sites (GOBT 2010; Goossen et al. 2011), but there is no information on the methodology and on the spatial location of the sites reported, making it a difficult task to include them in the geodatabase. In addition, we found some isolated visitor estimates in separate visitor monitoring studies (Hein et al. 2006; Jaarsma and Kooij 2010; Ligtenberg et al. 2008; Nunes et al. 2005).

Although most of the Southern European countries show less experience with visitor monitoring and counting, many visitor estimates were found for sites in Italy, some of them in combination with a monetary valuation study (Tempesta 2010), but most focusing solely on visitor numbers as a value indicator of different sites (Sanesi et al. 2008; Tempesta et al. 2002). Nevertheless, the methodological reporting was limited in most publications except Lehar et al. (2004). In particular, the study area definitions are deficient in many cases and consequently, it was not possible to locate part of the case study areas.

The countries Sweden and Finland show strong activity in visitor monitoring, but seem to have a slightly different focus. Studies are mainly concerned with on-site visitor managing and the quality of the recreational experiences, and less on highlighting the recreational economic value and importance, by publishing total visitor numbers. General population surveys resulting in outdoor recreation demand inventories are applied widely, but do not offer site-specific numbers (Kajala et al. 2006; Kajala et al. 2007; Sievänen et al. 2008; Sievänen 2012). We were able to obtain visitor numbers based on on-site counting for all national parks and some other official recreational sites. Most of these estimates are based on institutionalised visitor monitoring programs including long time series of visitor counting. Metsähallitus, a Finnish state-owned enterprise, runs electronic counters continuously in national parks and recreational areas. Summary reports in English and study area maps are available online, but no detailed methodological reporting is included (Metsähallitus 2015). Swedish visitor numbers including basic information on the methodology, such as counting devices etc. were obtained on request via email (Nasstrom 2012). Further visitor estimates for urban forests and other sites are indicated in literature, but it was not possible to obtain them (Ankre and Fredman 2012a; Fredman et al. 2012). 
Alternatively for Norway, it was possible to obtain only a single visitor estimate for one site. Even though visitor monitoring is not as widespread as in the other Scandinavian countries, more visitor estimates exist from on-site counting (Andersen et al. 2012; Andersen et al. 2014). More than 13 national recreation surveys were conducted in Norway, which might also include site-specific numbers (Aasetre 2008; Kajala et al. 2006).

In Germany, intensive visitor counting programs have evolved only in recent years. The recreational value of nature areas has been approached less in a quantitative manner by research and policy documents than in other countries (Mann 2007). Even though some economic valuation studies on recreation exist (Elsasser and Meyerhoff 2007), we could obtain visitor numbers only for national parks provided by studies that are mainly supervised by Hubert Job from the University of Würzburg (Job et al. 2003; 2005; 2010; Job and Stein 2010). Müritz national park is the only area for which we found time-series of total visitors (NPA 2010). Nevertheless, in 2011 the Federal Agency for Nature Conservation initiated a socioeconomic monitoring program, which resulted in visitor monitoring and counting activities in several protected areas.

In France and Spain the situations are similar. We obtained visitor numbers of national parks and some single additional sites only, but without reference to the applied methodologies. Nevertheless, visitor estimates have existed for all Spanish national parks for several years. Only very few publications on visitor monitoring and recreational valuation are published in English and language barriers made it difficult to derive further information on the visitor monitoring activities. We found some studies on the economic valuation of recreation, indicating that further visitor numbers exist in France, but could not obtain them (Bonnieux and Rainelli 2003; Scherrer 2003).

In Austria and Switzerland some isolated studies were found that provided visitor numbers to most national parks and some other sites. Studies result from individual initiatives of researchers and site managers. We could not identify an institutional setting for collecting such data across sites. In Austria, the team of Arne Arnberger from BOKU University is active in visitor monitoring, but focuses more on aspects such as evaluating device accuracy (Arnberger et al. 2005), crowding effects (Arnberger and Brandenburg 2007) or visitor structures (Arnberger and Brandenburg 2002), than on the recreational value of various recreation sites.

Language barriers particularly hindered the search for visitor numbers in eastern and southeastern Europe. Nevertheless, also thanks to the helpfulness of stakeholders, we could obtain visitor numbers and spatial information for all national parks in Poland and Hungary. An evaluation of general visitor monitoring activities in Eastern Europe beyond these activities was only possible in parts. We found some isolated studies offering visitor estimates for single sites in Slovakia (Taczanowska 2004) and in the Czech Republic (Cihar et al. 2008a; Cihar et al. 2008b). For the Baltic countries, only one estimate was discovered in Latvia, although some publications indicate growing activities in visitor monitoring (Kajala et al. 2006; Livina 2014). We obtained some visitor numbers from an extensive visitor counting in Estonian forest- and national parks, but they were not yet not scaled up to an annual basis (Karoles \& Maran 2014; Roose \& Sepp 2012; Vítek 2012).

In addition, we obtained some visitor estimates from isolated studies also for Croatia (Lukač 2002; Pettenella 2008), Slovenia (Erhartic et al. 2012), Belgium (Doidi et al. 2012; Gilissen and Van Den Bosch 2013), Iceland (Ólafsson 2012) and Ireland. Several of the Irish visitor estimates are part of economic valuation studies (Cronin et al. 2000; Cullinan et al. 2008a; Hynes and Hanley 2006). Even though some visitor monitoring take place, we could not obtain any total annual visitor estimate for a specific case study area in Portugal (de Oliveira and Mendes 2014; Mendes et al. 2012), in Greece (Xanthopoulou 2007) and in Cyprus (Kakouris 2007). 


\subsection{Proposed Reporting Standard for Visitor Counting}

Surprisingly, visitor monitoring studies and in particular visitor counting are typically characterised by relatively rudimentary reporting on the applied methodologies and study areas. In many publications not even the case study area is sufficiently defined, although this information is crucial because recreational behaviour has a highly spatial dimension. The size of the study area is fundamental for defining the average visitors per hectare, which is the most important indicator to assess the recreational value of different landscapes and to compare different recreational sites. Geo-locating the case study area - by some centroid coordinates, or better by displaying clear borders of the site - is essential for assessing any characteristics of the site not reported in the study itself. Even if the study estimates visitor numbers of a national park, the definition of the case study area is not always as clear as someone may expect. National parks may consist of zones of different protection levels and its borders may change over time. For many studies, study area identification is impossible without contacting the authors. If the monitored site cannot be identified, then what is the use of the estimated visitor numbers? Researchers may want to use the data for future research, acquire further information on the site, compare it to other sites and may display it on larger scale GIS maps. For identifying ecosystem characteristics and landscape features that attract recreational visitors, accurate, spatially explicit and fine-resolution visitor estimates are required.

The methodologies used to estimate total recreational visitors are manifold and may have a substantial effect on the accuracy of the result and may introduce a systematic bias. Even though some publications call for standardised visitor monitoring programs (Kajala et al. 2006; Kajala et al. 2007), the used methodologies will never be the same across all studies. Detailed reporting standards allow for comparing different studies by controlling for the effects of different methodologies. Statistical analysis in terms of meta-analysis (a common procedure in many other disciplines) is a helpful tool to identify effects of different methods on study results as well as the effects of different ecosystem characteristics. Thereby, intra-area comparison can be done even though non-standardised approaches are used, and drivers of recreational use can be identified. In addition, methods for estimating total visitors numbers can evolve and new ways of recreational use estimation can develop. New data sources such as GPS tracking, remote sensing and social media data, may allow for new methods of visitor number estimation.

We therefore propose a reporting standard for recreational visitor counting studies in a language accessible to the international research community (Table 1). All the methodological aspects that may have an impact on the final visitor estimates should be reported. A spreadsheet template for visitor counting reporting can be found in the appendix of this chapter. This could be used as a minimum requirement for peer reviewed publications that contain visitor counting. The spreadsheet template contains a "must have reporting standard" sheet, which is considered to be the absolute minimum methodological and spatial reporting on visitor counting studies, a "should have reporting standard" sheet, which we strongly recommend in order to allow statistical analysis of different methodological variables and a "nice to have reporting standard" sheet, which contains more detailed reporting options on the spatial distribution of visitors and visitor counting within the study area. The template is flexible as it allows users to add new variables and questions in order to fit it to specific user needs and to be extended to more general visitor monitoring studies. 
Table 2: Proposed reporting standard for visitor counting studies.

\begin{tabular}{|c|c|}
\hline Methodology & Description \\
\hline Study area & $\begin{array}{l}\text { A clear definition of the study area including information on the size and location, } \\
\text { preferably by a GIS shape file, otherwise by a map illustration in combination with } \\
\text { reference coordinates; } \\
\text { Further information on the type of ecosystem and the availability of recreational } \\
\text { facilities such as trail length, activities offered, visitor centres, etc. }\end{array}$ \\
\hline Year & $\begin{array}{l}\text { Declaration of data collection periods and the year that are correlated with the final } \\
\text { visitor estimates. }\end{array}$ \\
\hline $\begin{array}{l}\text { Counting } \\
\text { methods }\end{array}$ & $\begin{array}{l}\text { Clear description of the counting methods used (on-site vs. off-site methods): } \\
\text { - On-site: direct vs. indirect methods; direct counting: personally, interviews, } \\
\text { automated counting via turnstiles, photoelectric counters, pressure } \\
\text { sensitive devices or video counters etc.; validation of automated counter } \\
\text { against false counts; Indirect methods: analysis of car parks, trace use, } \\
\text { garbage, ticket sales or deterioration of certain facilities; self-registration } \\
\text { via guest books and boxes at summits or huts etc.; use of related statistic } \\
\text { such as overnight stays in hotels etc. } \\
\text { Off-site: catchment population interviews via post, telephone or personally, } \\
\text { expert judgment. } \\
\text { Detailed description of visitor counting methods can be found in (Cessford and } \\
\text { Muhar 2003; Muhar and Arnberger 2002). }\end{array}$ \\
\hline $\begin{array}{l}\text { Number of } \\
\text { counts / } \\
\text { interviews }\end{array}$ & $\begin{array}{l}\text { The number of interviews taken and / or of counts made in order to estimate the } \\
\text { total visitor numbers for the study area; the refusal rate of interviews and the } \\
\text { targeted survey population }\end{array}$ \\
\hline $\begin{array}{l}\text { Type of } \\
\text { visitors } \\
\text { counted }\end{array}$ & $\begin{array}{l}\text { The type of visitors, if only a certain type of visitors is assessed, such as defined by } \\
\text { the type of activities (anglers, hikers or boaters), mode of transport or length of } \\
\text { stay (day trip vs. overnight) }\end{array}$ \\
\hline $\begin{array}{l}\text { Spatial and } \\
\text { temporal } \\
\text { counting } \\
\text { resolution }\end{array}$ & $\begin{array}{l}\text { The counting resolution including information on the number and length of } \\
\text { counting, number of counting samples and number of counting locations; the time } \\
\text { of counting (day time, week days, months, seasons); the type of counting locations } \\
\text { (entrance point, central hub, peripheral location etc.); coordinates of counting } \\
\text { locations; selection of counting locations and temporal counting samples (random, } \\
\text { systematic) }\end{array}$ \\
\hline $\begin{array}{l}\text { Up-scaling } \\
\text { methodology }\end{array}$ & $\begin{array}{l}\text { Methodology used to scale-up counting samples to entire area and entire year } \\
\text { (temporal: all-year counting, visitor interview information, expert guessing, } \\
\text { temporal trends, accounting for weather etc.; spatial: comprehensive all entrance } \\
\text { points counting, statistical modelling, trend analysis, visitor interview information, } \\
\text { expert guessing) }\end{array}$ \\
\hline
\end{tabular}

In collaboration with the TAPAS Group, IUCN and the WCPA, the visitor counting reporting template has also been translated into a web interface that allows users to report their visitor counting studies online and obtain a filled spread sheet. The web interface is meant to automate visitor data collection 
and to construct a global visitor database that will be shared via http://esp-mapping.net. Please visit the site and encourage everybody to share their data at http://rris.biopama.org/visitor-reporting.

\section{Discussion}

Detailed reporting of the visitor counting methodology is of great importance for two reasons. First, it enables readers to distinguish sound studies from rudimentary ones. Some visitor numbers circulating in the web may result from an unverified guess only, whereas others are based on long-term intensive visitor counting and monitoring programs and therefore are far more reliable. Visitor data quality has been given little consideration in secondary research (Hill and Courtney 2006), partly because the lack of given information makes it difficult to judge the quality of the visitor estimates. Empirical findings in Schägner et al. (2016a) indicate that rough guesses have the tendency of over-estimating visitor numbers. Managers and stakeholders may tend to exaggerate the recreational importance of their sites, as for example, in the case of Harz national park in Germany. Initial visitor numbers circulated by the national park administration amounted to about 45 million visitors a year (Mehnen 2005; Ruschkowski 2010), but this estimate was reduced later, first to 10 million (Lehar et al. 2004), then to about 4 million ('Nationalpark Harz' 2015), and finally, after a solid visitor monitoring to 1.7 million (Job et al. 2014). The counting method and the spatial and temporal counting resolution may be a good indicator of the uncertainties involved with visitor estimates. Visitor counting programs that are based on a few and short counting periods at a few counting locations across a large study area, require more assumptions to be made in order to generate the total visitor estimate. These assumptions should be made transparent. Presently, relatively cheap visitor counting devices are available allowing for remote access and thus comprehensive visitor counting within recreational areas is on a rise. Reporting on the used methodology becomes therefore even more important in order to distinguish reliable results from the vast amount of unverified numbers published on the web.

Second, methodological reporting allows for conducting meta-analysis of multiple visitor counting studies and thereby estimates how different recreational sites characteristics and counting methods may affect estimated visitors. This may help to improve visitor counting methods and give insights into the drivers of recreational use. Meta-analysis of multiple studies is common in various disciplines to synthesise research findings and identify patterns among study results, the effects of methodological choices and the effects of study object characteristics that may be observed by analysing multiple studies. It has a long history, mainly in epidemiology (Deeks et al. 2001) and clinical trials (DerSimonian and Laird 1986), but also in environment economic valuation (Rosenthal and DiMatteo 2001) psychology (Lipsey and Wilson 2000) or ecology (Claudet et al. 2008). Quality and methodological reporting standards are prerequisite for a successful application.

The collection of high quality, standardized and spatially explicit statistics of the number of visitors is also relevant for recreational service mapping and spatial modelling, which is one major input for natural capital accounting. Real world observation of recreational use is required to calibrate and validate geo-statistical models for ecosystem service mapping (Schägner et al. 2013). The EU 7th Environment Action Programme (EAP) and the EU Biodiversity Strategy include objectives to develop natural capital accounting (NCA) in the EU, with a focus on ecosystems and their services. In 2015, the European Commission has launched a dedicated initiative called INCA (Integrated system of Natural Capital and ecosystem services Accounting). The data collected in this study and our call for a reporting standard constitute a first valuable input to developing accounts which track the recreational use of nature in the EU over time (EKC 2015).

Ideally, for a spatial ecosystem service model calibration, study sites of primary data collection would be randomly selected, as done for example in ecology for estimating species distributions (Keirle 2002). Random sampling is of great importance to obtain unbiased estimators in regression analysis. 
Nevertheless, the visitor data presented in this paper is strongly biased towards sites being prone of receiving high recreational visitor numbers, such as national parks or other protected areas. However, the aim of many visitor counting exercises as well as of spatial recreational service modelling is to highlight the recreational value or importance of certain ecosystems as compared to others. Therefore, it is not only important to know how many people visit a specific national park or recreational area, but also how few people visit an ordinary landscape. We therefore encourage the collection of visitor data for the general countryside and not only for specific recreational areas.

Finally, data sharing offers great benefits to science in general by allowing researchers to access multiple data sets at low costs and to combine them into valuable findings. Information technologies, metadata tools and repositories offer great opportunities for data sharing and many online data sharing tools have evolved (Drakou et al. 2015; JRC 2015). The Digital Observatory for Protected Areas (DOPA, http://dopa.jrc.ec.europa.eu/), for example, provides a set of web services and applications that can be used primarily to assess, monitor, report and possibly forecast the state of and the pressure on protected areas at multiple scales (Dubois et al. 2013; 2015). The data, indicators, maps and tools provided by the DOPA can be used to support spatial planning, resource allocation, protected area development and management as well as national and international reporting by a number of endusers including policy makers, funding agencies, protected area agencies and managers, researchers and the Convention on Biological Diversity (CBD). Although currently following a top-down approach that provides local data derived from global data sets, it is the objective of the forthcoming Open DOPA to capture information from the ground by allowing end-users to submit local information on the presence of key species, threats and pressures, projects, infrastructure and recreational visitors. Sharing visitor numbers through our web interface at rris.biopama.org/visitor-reporting presents a first contribution to the Open DOPA and will allow researchers to easily access, visualise and further analyse such data to better understand recreational patterns and stimulate the exchange of ideas and knowledge.

\section{Conclusion}

We reviewed visitor monitoring activities across Europe with a special focus on visitor counting and composed a geo-database on annual recreational visitor numbers to non-urban ecosystems across Europe, including 1,267 observations of 518 separate case study areas. The database gives insights into visitor monitoring and counting activities and recreation trends across Europe and it highlights the importance of recreation as an ecosystem service of non-urban ecosystems. Based on the review, we identify shortcomings and fields of improvements for future visitor monitoring and counting activities. In particular, we find that the presentation of results and methodologies is relatively unsatisfactory compared to other disciplines. Therefore, we propose a general reporting standard template for visitor counting studies with a special focus on: (1) case study area definition, (2) methodology documentation and ( 3 ) data sharing. It is meant to increase visitor monitoring professionalism and its scientific perception, and to facilitate the use of data for further research as well as the exchange of knowledge.

Visitor monitoring has moved on from sole visitor counts towards a manifold research topic, focusing on a variety of aspects such as visitor experiences, needs, attitudes and perceptions as well as activities, movement patterns, crowding effects, conflicts and wildlife disturbance (Aoki et al. 2014; Loomis 2000). However, it is necessary to note that simple visitor numbers are still a crucial piece of information and missing accurate visitor estimates are still a major obstacle in site management and secondary research (Booth 2006; Eagles 2014; Hill and Courtney 2006; Loomis 2000). Information on total recreational use is essential for assessing the value and importance of different nature areas for recreation and for identifying the determining factors of different sites' recreational values, but also 
for estimating visitors' impacts on resources, recreational facility management, budget allocation, for assessing the economic contribution of tourism and finally to defend recreational areas against competing uses. Advancements in automated visitor counting technologies, but also new data sources such as GPS tracking, drones, high resolution satellite imaginary, social media data, mobile phone traffic and smart phone apps may allow for more accurate and precise visitor estimates at lower costs.

By sharing data across the scientific community via online data sharing tools, the data provides a valuable asset for secondary research activities. The importance of reliable, comparable and accessible recreational visitor statistics has been recognised within the scientific community (Engels 2016; Spenceley 2016). Therefore, we aim at facilitating the reporting on visitor counting studies as well as the sharing of visitor data by providing a new web interface that allows users to insert their data. Please visit and promote our web interface and contribute to a global database on recreational visitor numbers in protected and nature areas at: rris.biopama.org/visitor-reporting.

\section{Acknowledgements}

This research was funded by the European Commission as part of the MAES (Mapping and Assessment of Ecosystems and their Services) working group and will be followed up on within the up-coming INCA (Integrated system of Natural Capital and ecosystem services Accounting) project as well as extended to ACP countries within the BIOPAMA programme and the rest of the world through the DOPA project.

We would like to thank everybody who supported our visitor data collection, in particular thanks to Ignacio Palomo and Fernando Santos from the Autonomous University of Madrid, Spain; Laurence Chabanis, Anne L'Epine and Bruno Lafage from Parcs nationaux de France; Hubert Job and Manuel Woltering from the University of Würzburg, Germany; Hartmut Rein from the University of Eberswalde, Germany; Christiane Gätje from Landesbetrieb Küstenschutz, Nationalpark und Meeresschutz Schleswig-Holstein, Germany; Tamara Keller from Hopp \& Partner, Germany; Heidrun Schütze from Amt für das Biosphärenreservat Schaalsee, Germany; Luisa Vogt from Fachhochschule Südwestfalen, Germany; Tina Gutowsky from Landesamt für Umwelt, Gesundheit und Verbraucherschutz Brandenburg, Germany; Barbara Engels from the Federal Agency for Nature Conservation, Germany; Luisa Vogt from Fachhochschule Südwestfalen, Germany; Frank Steingaß from Nationalpark Harz, Germany; Bert De Somviele from Organisation for Forest in Flanders, Belgium; Johan Van Den Bosch and Jeroen Gilissen from Regionaal Landschap Kempen en Maasland, Belgium; Eliza Romeijn-Peeters from Tandemmedewerker Vereniging voor Bos in Vlaanderen, Belgium; Rik De Vreese from Vrije Universiteit Brussel, Belgium; Martin Goossen from Alterra, Netherlands; Jasper Beekhoven from Recreatie Noord-Holland, Netherlands; Arne Arnberger and Thomas Schauppenlehner from BOKU, Austria; David Baumgartner from NP Hohe Tauern, Austria; Angelika Thaller from Österreichische Naturparke, Austria; Harald Gross from Wiener Umweltschutzabteilung, Austria; Sabine Hennig from Universität Salzburg, Austria; Karlheinz Erb from Alpen-Adria University, Austria; Martha Schober from Nationalpark Thayatal, Austria; Mette Termansen from Aarhus University, Denmark; Mette Rohde from Visitdjursland, Denmark; Bo Bredal Immersen from Thy NP, Denmark; Mette BindesbøII Nørregård from Friluftspolitisk konsulent, Denmark; Camilla Nasstrom and Stefan Henriksson from Naturvardsverket, Sweden; Peter Fredman from Mid-Sweden University; Kajala Liisa from Metsähallitus, Finland; Marjo Neuvonen and Eija Pouta from Luke, Finland; Leena Kopperoinen from Ymparisto, Finland; Krystyna Skarbek from the Ministry of the Environment, Poland; Annamária Kopek and Anna Knauer from Balaton NP, Hungary; Irena Muskare from Nature Conservation Agency, Latvia; Antti Roose from the University of Tartu, Estonia; Tiziano Tempesta from University of Padova, Italy; Alessandra Amoroso from Regione del Veneto, Italy; Sonia Trampetti from Consiglio Nazionale delle Ricerche, Italy; Laura Casti from Parks.it, Italy; Colin Hossack from Galloway 
Forest District, Ireland; Hans-Ulrich Zaugg from the Eidgenössisches Departement des Innern, Switzerland; Ronald Schmidt from Universität Zürich-Irchel, Switzerland; Ondrej Vitek from the Agentura ochrany prirody a krajiny CR Odbor zvlastni ochrany prirody Kaplanova, Czech Republic; Eray Caglayan from Orman ve Su İsleri Bakanlığı Doğa Koruma ve Milli Parklar Genel Müdürlüğü Söğütözü, Turkey; Nidos Lankytoju Centras from the Visitors centre of Kursiu nerija national park Nagliu, Lithuania; Porvarður Árnason from University of Iceland; Erodotos Kakouris from Cyprus Forestry Department; Ricardo M. Nogueira Mendes from Universidade Nova de Lisboa, Portugal; Jake Morris and Kieron Doick from Forest Research, UK; Ian Bateman from University of Exeter, UK; Daniel Lowe and Andy Jones from University of East Anglia, UK; Abbie McPhie from VisitEngland, UK; special thanks to Sheila Ward and David Cross from the Forestry Commission, UK and everyone we forgot to mention here.

Besides we would like to thank our colleagues Bastian Bertzky, Andreas Brink, Jürgen Meyerhoff, Andrea Mandrici, James Davy and Lucy Bastin for helpful comments.

\section{References}

Aasetre, J. (2008). 'Norway: (COST E33 WG2 Country Report), Recreation and nature tourism demand, supply and actual usage'. Sievänen T., Arnberger A., Dehez J., Grant N., Jensen F. S., \& SkovPetersen H. (eds) Forest Recreation Monitoring - A European Perspective, Working Papers of the Finnish Forest Research Institute, pp. 212-5. Helsinki.

Andersen, O., Gundersen, V., Wold, L. C., \& Stange, E. (2012). 'Counting visitors in alpine areas: how sensor range, clothing, air temperature and visitor volume affects passive infrared counter accuracy'. International Conference on Monitoring and Management of Visitor Flows in Recreational and Protected Areas (MMV), pp. 30-1. Stockholm, Sweden.

Andersen, O., Gundersen, V., Wold, L. C., \& Stange, E. (2014). 'Monitoring visitors to natural areas in wintertime: issues in counter accuracy', Journal of Sustainable Tourism, 22/4: 550-60. DOI:

10.1080/09669582.2013.839693

Ankre, R., \& Fredman, P. (2012). 'Visitor monitoring from a management perspective - experiences from Sweden'. International Conference on Monitoring and Management of Visitor Flows in Recreational and Protected Areas (MMV), pp. 26-7. Stockholm, Sweden.

Aoki, Y., Rupprecht, C., \& Kumagal, K. (2014). 'Recreation research trends of MMV, 2002-2012'. International Conference on Monitoring and Management of Visitor Flows in Recreational and Protected Areas (MMV), pp. 280-2. Tallinn, Estonia.

Arnberger, A., \& Brandenburg, C. (2002). 'Visitor Structure of a Heavily Used Conservation Area: The Danube Floodplains National Park, Lower Austria'. International Conference on Monitoring and Management of Visitor Flows in Recreational and Protected Areas (MMV), pp. 7-13. Vienna, Austria: Institute for Landscape Architecture and Landscape Management, Bodenkultur University.

Arnberger, A., \& Brandenburg, C. (2007). 'Past on-site experience, crowding perceptions, and use displacement of visitor groups to a peri-urban national park', Environmental Management, 40/1: 3445. DOI: $10.1007 /$ s00267-004-0355-8

Arnberger, A., Haider, W., \& Brandenburg, C. (2005). 'Evaluating visitor-monitoring techniques: a comparison of counting and video observation data', Environmental Management, 36/2: 317-27. DOI: 10.1007/s00267-004-8201-6 
Balmford, A., Green, J. M. H., Anderson, M., Beresford, J., Huang, C., Naidoo, R., Walpole, M., et al. (2015). 'Walk on the Wild Side: Estimating the Global Magnitude of Visits to Protected Areas', PLoS Biol, 13/2: e1002074. DOI: 10.1371/journal.pbio.1002074

Bateman, I. J., Brainard, J. S., \& Lovett, A. A. (1998). 'Transferring multivariate benefit functions using geographical information systems', Nota di lavoro / Fondazione ENI Enrico Mattei / ENV, Environmental economics, 84.

Bateman, I. J., Day, B. H., Georgiou, S., \& Lake, I. (2006). 'The aggregation of environmental benefit values: Welfare measures, distance decay and total WTP', Ecological Economics, Environmental Benefits Transfer: Methods, Applications and New Directions Benefits Transfer, 60/2: 450-60. DOI: 10.1016/j.ecolecon.2006.04.003

Bateman, I. J., \& Jones, A. P. (2007). 'Contrasting conventional with multi-level modeling approaches to meta-analysis: Expectation consistency in UK woodland recreation values'. Environmental Value Transfer: Issues and Methods, pp. 131-60.

Bonnieux, F., \& Rainelli, P. (2003). 'Lost Recreation and Amenities: The Erika Spill Perspectives'. International scientific seminar : Economic, social and environmental effects of the 'Prestige' oil spill (2003-03-07). Santiago de Comostella.

Booth, K. (2006). Review of visitor research for the Department of Conservation ( No. 229). DOC RESEARCH \& DEVELOPMENT SERIES. Wellington, New Zealand.

BR, (Beaufort Research). (2008). Visits to Tourist Attractions in Wales 2007, Report for Visit Wales., p. 65. Cardiff, UK.

BR, (Beaufort Research). (2012). Visits to Tourist Attractions in Wales 2011, Report for Visit Wales., p. 70.

Brandenburg, C., Muhar, A., \& Taczanowska, K. (2008). 'Potential and limitations of GPS tracking for monitoring spatial and temporal aspects of visitor behaviour in recreational areas.' International Conference on Monitoring and Management of Visitor Flows in Recreational and Protected Areas (MMV), pp. 451-5. Montecatini Terme, Italy.

CBD, (Convention on Biological Diversity). (2010). DECISION ADOPTED BY THE CONFERENCE OF THE PARTIES TO THE CONVENTION ON BIOLOGICAL DIVERSITY AT ITS TENTH MEETING: $X / 2$. The Strategic Plan for Biodiversity 2011-2020 and the Aichi Biodiversity Targets., p. 13. Nagoya, Japan.

Cessford, G., \& Muhar, A. (2003). 'Monitoring options for visitor numbers in national parks and natural areas', Journal for Nature Conservation, 11/4: 240-50. DOI: 10.1078/1617-1381-00055

Cihar, M., Trebicky, V., \& Stankova, J. (2008a). 'Analysis of Nature-Based Tourism in the Sumava National Park, Czech Republic: 1997-2004'. International Conference on Monitoring and Management of Visitor Flows in Recreational and Protected Areas (MMV), pp. 271-7. Montecatini Terme, Italy.

Cihar, M. (2008b). 'Stakeholder's monitoring and involvement: management option for Sumava National Park (Czech Republic)'. International Conference on Monitoring and Management of Visitor Flows in Recreational and Protected Areas (MMV), pp. 271-6. Montecatini Terme, Italy.

Claudet, J., Osenberg, C. W., Benedetti-Cecchi, L., Domenici, P., García-Charton, J.-A., Pérez-Ruzafa, A., Badalamenti, F., et al. (2008). 'Marine reserves: size and age do matter', Ecology Letters, 11/5: 481-9. DOI: 10.1111/j.1461-0248.2008.01166.x 
Coghlan, A. (2012). 'Satellite images help doctors count people from space'. New Scientist. Retrieved August 3, 2016, from <https://www.newscientist.com/article/dn21846-satellite-images-helpdoctors-count-people-from-space/>

Cole, D. N. ; (2006). 'Visitor and recreation impact monitoring: Is it lost in the gulf between science and management?'. The George Wright Society Forum, Vol. 2, p. 1116.

Cope, A., Doxford, D., \& Probert, C. (2000). 'Monitoring visitors to UK countryside resources: The approaches of land and recreation resource management organisations to visitor monitoring', Land Use Policy, 17/1: 59-66. DOI: 10.1016/\$0264-8377(99)00035-6

Crespo Godinho de Oliveira, J. N., \& Nogueira Mendes, C. (2014). 'Outdoor recreation and visitor profile of protected areas in Portugal'. Monitoring and Management of Visitor Flows in Recreational and Protected Areas, pp. 24-6. Tallinn, Estonia.

Cronin, C., McCarthy, J., O'Leary, K., \& Luddy, P. J. (2000). The people's landscape. A study of the Killarney National Park. The Travel and Tourism Programme in Ireland, p. 21. St. Brendan's College.

Cullinan, J., Hynes, S., \& O’Donoghue, C. (2008). 'Aggregating Consumer Surplus Values in Travel Cost Modelling Using Spatial Microsimulation and GIS', RERC Working Paper Series, 08-WP-RE-07.

Deeks, J. J., Altman, D. G., \& Bradburn, M. J. (2001). 'Statistical Methods for Examining Heterogeneity and Combining Results from Several Studies in Meta-Analysis'. Egger M., Smith G. D., \& Altman D. G. (eds) Systematic Reviews in Health Care, pp. 285-312. BMJ Publishing Group.

DEIMS, (Drupal Ecological Information System). (2015). 'Repository for Research Sites and Datasets'. Retrieved August 20, 2015, from <http://data.Iter-europe.net/deims/>

DerSimonian, R., \& Laird, N. (1986). 'Meta-analysis in clinical trials', Controlled Clinical Trials, 7/3: 177-88. DOI: 10.1016/0197-2456(86)90046-2

Doidi, L., Colson, V., \& Vanwijnsberghe, S. (2012). 'Using automatic counters and GPS technology for recreation monitoring: case of Sonian Forest (Brussels, Belgium)'. International Conference on Monitoring and Management of Visitor Flows in Recreational and Protected Areas (MMV), pp. 344-6. Stockholm, Sweden.

Drakou, E. G., Crossman, N. D., Willemen, L., Burkhard, B., Palomo, I., Maes, J., \& Peedell, S. (2015). 'A visualization and data-sharing tool for ecosystem service maps: Lessons learnt, challenges and the way forward', Ecosystem Services. DOI: 10.1016/j.ecoser.2014.12.002

Eagles, P. F. J. (2014). 'Research priorities in park tourism', Journal of Sustainable Tourism, 22/4: 52849. DOI: $10.1080 / 09669582.2013 .785554$

EEA, (European Environment Agency). (2013). 'CDDA (Common Database on Designated Areas)'. CDDA (Common Database on Designated Areas). Retrieved July 16, 2015, from <http://www.eea.europa.eu/data-and-maps/data/nationally-designated-areas-national-cdda-4>

Eigenbrod, F., Armsworth, P. R., Anderson, B. J., Heinemeyer, A., Gillings, S., Roy, D. B., Thomas, C. D., et al. (2010). 'Error Propagation Associated with Benefits Transfer-Based Mapping of Ecosystem Services', Biological Conservation, 143/11: 2487-93. DOI: 10.1016/j.biocon.2010.06.015

EKC, (Environment Knowledge Community). (2015). Knowledge innovation project (KIP) on Accounting for natural capital and ecosystem services - scoping paper., p. 7. Ispra, Italy. Retrieved from <http://ec.europa.eu/environment/nature/capital_accounting/pdf/KIP-INCAScopingPaper.pdf> 
Elsasser, P., \& Meyerhoff, J. (2007). A Bibliography and Data Base on Environmental Benefit Valuation Studies in Austria, Germany and Switzerland Part I: Forestry Studies. (Z. H. U. Hamburg, Ed.) Arbeitsbericht des Instituts für Ökonomie 2007 / 01. Hamburg.

Engels, B. (2016). 'Visitors count! - Count visitation! Tourism in protected areas as a driver for socioeconomic development - standard setting and implementation'. IUCN World Conservation Congress. Hawaii, USA.

Erhartic, B., Smrekar, A., \& Hribar, M. S. (2012). 'Protected area within the city: Monitoring and management of visitors in Landscape park Tivoli, Rožnik and Šišenski Hrib in Ljubljana (Slovenia)'. International Conference on Monitoring and Management of Visitor Flows in Recreational and Protected Areas (MMV), pp. 242-5. Stockholm, Sweden.

EU BON, (Biodiversity Observation Network), \& GBIF, (Global Biodiversity Information Facility). (2015). Publishing sample data using the GBIF IPT., p. 10. Retrieved from <http://links.gbif.org/iptsample-data-primer>

FC, (Forestry Commission, UK). (2015). 'Forestry Commission - Statistics - Visitor Surveys \& Counts'. Retrieved August 20, 2015, from <http://www.forestry.gov.uk/forestry/infd-5pgazz>

Fredman, P., Lindhagen, A., \& Nordström., G. (2012). 'Monitoring outdoor recreation trends in Sweden'. International Conference on Monitoring and Management of Visitor Flows in Recreational and Protected Areas (MMV), pp. 80-2. Stockholm, Sweden.

Fredman, P., Romild, U., Emmelin, L., \& Yuan, M. (2009). 'Non-Compliance with On-Site Data Collection in Outdoor Recreation Monitoring', Visitor Studies, 12/2: 164-81. DOI: 10.1080/10645570903203471

Fretwell, P. T., LaRue, M. A., Morin, P., Kooyman, G. L., Wienecke, B., Ratcliffe, N., Fox, A. J., et al. (2012). 'An Emperor Penguin Population Estimate: The First Global, Synoptic Survey of a Species from Space', PLoS ONE, 7/4. DOI: 10.1371/journal.pone.0033751

Fretwell, P. T., Staniland, I. J., \& Forcada, J. (2014). 'Whales from Space: Counting Southern Right Whales by Satellite', PLOS ONE, 9/2: e88655. DOI: 10.1371/journal.pone.0088655

Gilissen, J., \& Van Den Bosch, J. (2013). 'Email (May 2013): visitor numbers'.

GOBT, (Gelders Overijssels Bureau voor Toerisme). (2007). Bezoek aan toeristische Attracties Gelderland, een analyse van de ontwikkelingen 2002-2006., p. 17. Deventer, Netherlands.

GOBT, (Gelders Overijssels Bureau voor Toerisme). (2009). Bezoek aan toeristische Attracties Gelderland, een analyse van de ontwikkelingen 2004-2008., p. 13. Deventer, Netherlands.

GOBT, (Gelders Overijssels Bureau voor Toerisme). (2010). Bezoek aan toeristische Attracties Gelderland, een analyse van de ontwikkelingen 2005-2009., p. 12. Deventer, Netherlands.

Goossen, C. M., Fontein, R. J., Donders, J. L. M., \& Arnouts, R. C. M. (2011). Mass Movement naar recreatieve gebieden: Overzicht van methoden om bezoekersaantallen te meten ( No. 243). werkdocumenten, p. 85. Wageningen, Netherlands.

Hadwen, W. L., Hill, W., \& Pickering, C. M. (2007). 'Icons under threat: Why monitoring visitors and their ecological impacts in protected areas matters', Ecological Management \& Restoration, 8/3: 177-81. DOI: 10.1111/j.1442-8903.2007.00364.x 
Hein, L., van Koppen, K., de Groot, R. S., \& van lerland, E. C. (2006). 'Spatial scales, stakeholders and the valuation of ecosystem services', Ecological Economics, 57/2: 209-28. DOI:

10.1016/j.ecolecon.2005.04.005

Hill, G. W., \& Courtney, P. R. (2006). 'Demand analysis projections for recreational visits to countryside woodlands in Great Britain', Forestry, 79/2: 185-200. DOI: 10.1093/forestry/cpl005

Hornback, K. E., \& Eagles, P. F. J. (1999). GUIDELINES for PUBLIC USE MEASUREMENT and REPORTING at PARKS and PROTECTED AREAS. Cambridge, UK: IUCN Publications Services Unit.

Hynes, S., \& Hanley, N. (2006). 'Preservation versus development on Irish rivers: whitewater kayaking and hydro-power in Ireland', Land Use Policy, 23/2: 170-80. DOI: 10.1016/j.landusepol.2004.08.013

IUCN, (International Union for Conservation of Nature=, \& UNEP, (United Nations Environment Programme). (2015). 'WDPA - World Database on Protected Areas'.

Jaarsma, R., \& Kooij, H.-J. (2010). 'Urban park as well as Nature 2000 area: monitoring and managing visitors and dogs'. Monitoring and Management of Visitor Flows in Recreational and Protected Areas, pp. 282-4. Wageningen, Netherlands.

Jensen, F. S. (1992). Vestamagers bes $\emptyset$ gstal, 1985-1988. Landbrugsministeriet, Forskningscentret for skov \& landskab.

Jensen, F. S. (2003). Friluftsliv i 592 skove og andre naturområder. Landbrugsministeriet, Forskningscentret for skov \& landskab.

Jensen, F. S., \& Guldager, S. (2005). Den rekreative brug af tre parker i Københavns Kommune: Enghaveparken, Fælledparken og Amager Fælled, 2003-2004. Københavns Kommune, Bygge- og Teknikforvaltningen, Vej \& Park.

Job, H., Harrer, B., Metzler, D., \& Hajizadeh-Alamdary, D. (2005). Ökonomische Effekte von Großschutzgebieten - Untersuchung der Bedeutung von Großschutzgebieten für den Tourismus und die wirtschaftliche Entwicklung der Region ( No. 135). BfN-Skripten, p. 119. Bonn, Germany.

Job, H., Metzler, D., \& Vogt, L. (2003). Inwertsetzung alpiner Nationalparks: Eine regionalwirtschaftliche Analyse des Tourismus im Alpenpark Berchtesgaden., 1st ed. Kallmünz/Regensburg: Laßleben, $M$.

Job, H., \& Stein, B. (2010). Der Nationalpark Sächsische Schweiz als regionaler Wirtschaftsfaktor ( No. 6). Schriftenreihe des Nationalparks Sächsische Schweiz, p. 40. Bonn, Germany.

Job, H., Woltering, M., \& Harrer, B. (2010). Regionalökonomische Effekte des Tourismus in deutschen Nationalparken., 1., Auflage. Bonn-Bad Godesberg: Landwirtschaftsvlg Münster.

Job, Hubert, Woltering, Manuel, Schamel, J., \& Merlin, C. (2014). Regionalökonomische Effekte des Nationalparks Harz., p. 91. Würzburg.

Johnston, R. J., \& Rosenberger, R. S. (2010). 'Methods, Trends and Controversies in Contemporary Benefit Transfer', Journal of Economic Surveys, 24/3: 479-510.

Jones, A., Bateman, I., \& Wright, J. (2003). Estimating arrival numbers and values for informal recreational use of British woodlands., p. 132. Norwich, UK: CSERGE School of Environmental Sciences University of East Anglia Norwich.

JRC, (Joint Research Centre, European Commission). (2015). 'DOPA (The Digital Observatory for Protected Areas)'. Retrieved from <http://dopa.jrc.ec.europa.eu/> 
Kajala, L., Almik, A., Dahl, R., Diksaite, L., Erkkonen, J., Fredman, P., Jensen, F., et al. (2007). Visitor monitoring in nature areas. A manual based on experiences from the Nordic and Baltic countries. Stockholm, Sweden: The Swedish Environmental Protection Agency.

Kajala, L., Søndergaard Jensen, F., Skov-Petersen, H., Erkkonen, J., Sievänen, T., Dikšaitė, L., \& Fredman, P. (2006). Monitoring Outdoor Recreation in the Nordic and Baltic Countries. Paris: Organisation for Economic Co-operation and Development.

Kakouris, E. (2007). 'Cyprus: (COST E33 WG2 Country Report), Recreation and nature tourism demand, supply and actual usage'. Sievänen T., Arnberger A., Dehez J., Grant, Jensen F. S., \& SkovPetersen H. (eds) Forest Recreation Monitoring - A European Perspective, Working Papers of the Finnish Forest Research Institute. Helsinki.

Kalisch, D. (2012). 'Relevance of crowding effects in a coastal National Park in Germany: results from a case study on Hamburger Hallig', Journal of Coastal Conservation, 16/4: 531-41. DOI:

$10.1007 / \mathrm{s} 11852-012-0195-2$

Karoles, K., \& Maran, K. (2014). 'More than ten years of visitor monitoring in Estonian state forests'. International Conference on Monitoring and Management of Visitor Flows in Recreational and Protected Areas (MMV), pp. 195-6. Tallinn, Estonia.

Koch, N. E. (1978). Skovenes friluftsfunktion i Danmark. I (Forest recreation in Denmark; part I). Kopenhagen, Denmark.

Koch, N. E. (1980). Skovenes friluftsfunktion i Danmark II, (Forest recreation in Denmark, part II). Kopenhagen, Denmark.

Koch, N. E. (1984). Skovenes friluftsfunktion i Danmark III, (Forest recreation in Denmark, part III). Kopenhagen, Denmark.

Lehar, G., Hausberger, K., \& Fuchs, L. (2004). Besucherzählung, Wertschöpfungs- und Motiverhebung im Nationalpark Hohe Tauern und im Naturpark Rieserferner-Ahrn., p. 90. Innsbruck, Austria: Institut für Verkehr und Tourismus.

Ligtenberg, A., van Marwijk, R., Moelans, B., \& Kuijpers, B. (2008). 'Recognizing patterns of movements in visitor flows in nature areas'. International Conference on Monitoring and Management of Visitor Flows in Recreational and Protected Areas (MMV), pp. 422-7. Montecatini Terme, Italy.

Lipsey, M. W., \& Wilson, D. (2000). Practical Meta-Analysis., 1st ed. Sage Publications, Inc.

Livina, A. (2014). 'Monitoring for tourism cluster in the Gauja National Park, Latvia'. International Conference on Monitoring and Management of Visitor Flows in Recreational and Protected Areas (MMV), pp. 203-5. Tallinn, Estonia.

Loomis, J. B. (2000). 'Counting on recreation use data: a call for long-term monitoring.', Journal of Leisure Research, 32/1: 93-6.

Loomis, J. B., \& Rosenberger, R. S. (2006). 'Reducing barriers in future benefit transfers: Needed improvements in primary study design and reporting', Ecological Economics, Environmental Benefits Transfer: Methods, Applications and New Directions Benefits Transfer, 60/2: 343-50. DOI:

10.1016/j.ecolecon.2006.05.006 
Lukač, G. (2002). 'The Visitor Flows and the Bird Communities in the Paklenica National Park, Croatia (between 1997-2001)'. Monitoring and Management of Visitor Flows in Recreational and Protected Areas Conference Proceedings, pp. 73-83. Wien, Austria.

Maes, J., Liquete, C., Teller, A., Erhard, M., Paracchini, M. L., Barredo, J. I., Grizzetti, B., et al. (2016). 'An indicator framework for assessing ecosystem services in support of the EU Biodiversity Strategy to 2020', Ecosystem Services, 17: 14-23. DOI: 10.1016/j.ecoser.2015.10.023

Maes, J., Teller, A., Erhard, M., Liquete, C., Braat, L., Berry, P., Egoh, B., et al. (2013). Mapping and Assessment of Ecosystems and their Services: An analytical framework for ecosystem assessments under Action 5 of the EU Biodiversity Strategy to 2020. Luxembourg: Publications office of the European Union.

Mann, C. (2007). 'Germany: (COST E33 WG2 Country Report), Recreation and nature tourism demand, supply and actual usage'. Sievänen T., Arnberger A., Dehez J., Grant, Jensen F. S., \& SkovPetersen H. (eds) Forest Recreation Monitoring - A European Perspective, Working Papers of the Finnish Forest Research Institute. Helsinki.

Maptionnaire. (2016). 'Maptionnaire is a SaaS for creating your own map-based questionnaires and civic participation platforms easily.' Retrieved August 11, 2016, from

<https://maptionnaire.com/de/>

McComb, G., Lantz, V., Nash, K., \& Rittmaster, R. (2006). 'International valuation databases:

Overview, methods and operational issues', Ecological Economics, Environmental Benefits Transfer: Methods, Applications and New Directions in Benefits Transfer S.I., 60/2: 461-72. DOI: 10.1016/j.ecolecon.2006.05.009

McMahon, C. R., Howe, H., Hoff, J. van den, Alderman, R., Brolsma, H., \& Hindell, M. A. (2014). 'Satellites, the All-Seeing Eyes in the Sky: Counting Elephant Seals from Space', PLOS ONE, 9/3: e92613. DOI: 10.1371/journal.pone.0092613

Mehnen, N. (2005). Die regionalwirtschaftliche Bedeutung des Nationalparktourismus: untersucht am Beispiel des neuen Nationalparks Harz (Diplomarbeit). Hochschule Vechta.

Metsähallitus. (2015). 'Parks et Wildlife Finland Annual Reports - www.metsa.fi'. Retrieved August 20, 2015, from <http://www.metsa.fi/web/en/parksetwildlifefinlandannualreports>

Morris, J., \& Doick, K. (2009). Annex 1: 'Flagship' Case Study Report Bentley Community Woodland, Monitoring \& Evaluating Quality of Life for CSR07., p. 46.

Muhar, A., \& Arnberger, A. (2002). 'Methods for Visitor Monitoring in Recreational and Protected Areas: An Overview'. Monitoring and Management of Visitor Flows in Recreational and Protected Areas. Presented at the Monitoring and Management of Visitor Flows in Recreational and Protected Areas, Vienna.

Nasstrom, C. (2012). 'Email: Swedish National Parks'.

'Nationalpark Harz'. (2015). Wikipedia.

NE, (Natural England). (2014). 'Monitor of Engagement with the Natural Environment: survey purpose and results - GOV.UK'. Retrieved August 20, 2015, from <https://www.gov.uk/government/collections/monitor-of-engagement-with-the-naturalenvironment-survey-purpose-and-results> 
Nogueira Mendes, R. M., Silva, A., Grilo, C., Rosalino, L. M., \& Silva, C. P. (2012). 'MTB monitoring in Arrábida natural Park, Portugal'. International Conference on Monitoring and Management of Visitors in Recreational and Protected Areas, pp. 32-3. Stockholm, Sweden.

NPA, (Nationalparkamt). (2010). Müritz Nationalpark: Jahresbericht., p. 53. Müritz, Germany.

Nunes, P. A. L. D., Heide, V. der, Martijn, C., Bergh, V. den, M, J. C. J., lerland, V., \& Ekko. (2005). Measuring the Economic Value of Two Habitat Defragmentation Policy Scenarios for the Veluwe, The Netherlands (SSRN Scholarly Paper No. ID 690146). Rochester, NY: Social Science Research Network. Retrieved August 2, 2015, from <http://papers.ssrn.com/abstract=690146>

Ólafsson, R. (2012). 'Tourist distribution in time and space: A case from the Icelandic Highlands'. International Conference on Monitoring and Management of Visitors in Recreational and Protected Areas, pp. 28-31. Stockholm, Sweden.

Pettenella, D. (2008). 'Recreational services economic evaluation and responsible management of protected areas: a case study in the Plitvice National Park (Croatia)'. Symposium on Emerging needs of society from forest ecosystems: towards the opportunities and dilemmas in forest managerial economics and accounting.

Roose, A., \& Sepp, K. (2012). 'Visitor monitoring from a management perspective - experiences from Sweden'. Balancing conservation and visitation through a comprehensive monitoring system of nature protection in Estonia, pp. 86-7. Stockholm, Sweden.

Rosenberger, R. S., \& Loomis, J. B. (2000). 'Using Meta-Analysis for Benefit Transfer: In-Sample Convergent Validity Tests of an Outdoor Recreation Database', Water Resources Research, 36/4: PP. 1097-1107. DOI: 200010.1029/2000WR900006

Rosenberger, R. S., \& Phipps, T. (2007). 'Correspondence and Convergence in Benefit Transfer Accuracy: Meta-Analytic Review of the Literature'. Navrud S. \& Ready R. (eds) Environmental Value Transfer: Issues and Methods, Vol. 9, pp. 23-43. Springer Netherlands: Dordrecht.

Rosenthal, R., \& DiMatteo, M. R. (2001). 'META-ANALYSIS: Recent Developments in Quantitative Methods for Literature Reviews', Annual Review of Psychology, 52/1: 59-82. DOI: 10.1146/annurev.psych.52.1.59

Ruschkowski, E. von. (2010). Ursachen und Lösungsansätze für Akzeptanzprobleme von Großschutzgebieten am Beispiel von zwei Fallstudien im Nationalpark Harz und im Yosemite National Park. Stuttgart: ibidem-Verlag.

Sanesi, G., Marco, F., Colangelo, G., \& Raffaele Lafortezza, G. (2008). 'Monitoring visitor-flows in Tuscany's forests: preliminary results and clues'. International Conference on Monitoring and Management of Visitor Flows in Recreational and Protected Areas (MMV), pp. 40-4. Montecatini Terme, Italy.

Schägner, J. P., Brander, L., Maes, J., \& Hartje, V. (2013). 'Mapping ecosystem services' values: Current practice and future prospects', Ecosystem Services, Special Issue on Mapping and Modelling Ecosystem Services, 4: 33-46. DOI: 10.1016/j.ecoser.2013.02.003

Schägner, J. P., Brander, L., Maes, J., Paracchini, M. L., \& Hartje, V. (2016a). 'Mapping recreational visits and values of European national parks by combining statistical modelling and unit value transfer', Journal for Nature Conservation, 31: 71-84. DOI: 10.1016/j.jnc.2016.03.001

Schägner, J. P., Paracchini, M. L., Brander, L., Maes, J., \& Hartje, V. (2016b). 'Mapping the Recreational Value of Non-Urban Ecosystems across Europe: Combining Meta-Analysis and GIS'. 
European Association of Environmental and Resource Economists 22nd Annual Conference. Zurich, Switzerland.

Scherrer, S. (2003). 'EVALUATION ECONOMIQUE DES AMENITES RECREATIVES D'UN PARC URBAIN: LE CAS DU PARC DE SCEAUX', DOCUMENT DE TRAVAIL, 3/E09: 62.

SDI4Apps. (2016). 'SDI4Apps: Project information'. SDI 4 Apps. Retrieved August 3, 2016, from <http://sdi4apps.eu/project-information/sdi4apps/>

Sen, A., Darnell, A., Crowe, A., Bateman, I. J., Munday, P., \& Foden, J. (2011). Economic Assessment of the Recreational Value of Ecosystems in Great Britain: Report to the Economics Team of the UK National Ecosystem Assessment., p. 38. The Centre for Social and Economic Research on the Global Environment (CSERGE), University of East Anglia.

Shresta, R., Rosenberger, R. S., \& Loomis, J. B. (2007). 'Benefit Transfer Using Meta-Analysis In Recreation Economic Valuation'. Environmental Value Transfer: Issues and Methods, The Economics Of Non-Market Goods And Resources, Vol. 9.

Sievänen, T. (2012). 'Counting visitors in alpine areas: how sensor range, clothing, air temperature and visitor volume affects passive infrared counter accuracy'. Monitoring outdoor recreation trends in Finland, pp. 30-1. Stockholm, Sweden.

Sievänen, T., Arnberger, A., Dehez, J., Grant, Jensen, F. S., \& Skov-Petersen, H. (2008). Forest Recreation Monitoring - A European Perspective. Working Papers of the Finnish Forest Research Institute. Helsinki.

Sievänen, T., Arnberger, A., Dehez, J., Jensen, S., Colson, V., Gentin, S., Granet, A. M., et al. (2009). 'Monitoring of forest recreation demand'. Adkins S., Simpson M., Tyrvainen L., Sievanen, T., \& Probstl U. (eds) European forest recreation and tourism : a handbook, pp. 105-33. Taylor \& Francis.

Spenceley, A. (2016). 'Personal Communication (May 2016): Visitor and Tourism Monitoring in IUCN Category II Protected Areas (National Parks): A Feasibility Study on Proof of Principle'.

Stanley, T. d., Doucouliagos, H., Giles, M., Heckemeyer, J. H., Johnston, R. J., Laroche, P., Nelson, J. P., et al. (2013). 'Meta-Analysis of Economics Research Reporting Guidelines', Journal of Economic Surveys, 27/2: 390-4. DOI: 10.1111/joes.12008

Stenovec, T. (2015). 'Google has gotten incredibly good at predicting traffic - here's how'. Tech Insider. Retrieved August 11, 2016, from <http://www.techinsider.io/how-google-maps-knowsabout-traffic-2015-11>

Taczanowska, K. (2004). 'The Potentials for Developing Cross-border Tourism between Poland and Slovakia in the Tatra Mountains'. International Conference on Monitoring and Management of Visitor Flows in Recreational and Protected Areas (MMV), pp. 404-7. Rovaniemi, Finland.

Tempesta, T. (2010). 'The recreational value of urban parks in the Veneto region (Italy)'. International Conference on Monitoring and Management of Visitor Flows in Recreational and Protected Areas (MMV), pp. 236-8. Wageningen, Netherlands.

Tempesta, T., Visintin, F., \& Marangon, F. (2002). 'Ecotourism demand in North-East Italy'. International Conference on Monitoring and Management of Visitor Flows in Recreational and Protected Areas (MMV), Vol. MMV 1-Proceedings, pp. 373-9. Vienna, Austria: Institute for Landscape Architecture and Landscape Management, Bodenkultur University. 
Termansen, M., Zandersen, M., \& McClean, C. J. (2008). 'Spatial Substitution Patterns in Forest Recreation', Regional Science and Urban Economics, 38/1: 81-97. DOI:

16/j.regsciurbeco.2008.01.006

TNS, (Travel \& Tourism), \& FCS, (Forestry Commission Scotland. (2006a). All Forests Visitor Monitoring Survey of visitors to FCS forests Year 2: June 2005 to May 2006., p. 85. Edinburgh, UK.

TNS, (Travel \& Tourism). (2006b). All Forests Visitor Monitoring Survey of visitors to FCS forests Year 1: June 2004 to May 2005., p. 86. Edinburgh, UK.

TNS, (Travel \& Tourism). (2008). All Forests Visitor Monitoring Survey of visitors to FCS forests Year 3: July 2006 to June 2007., p. 90. Edinburgh, UK.

TNS, (Travel \& Tourism), \& FCW, (Forestry Commission Wales). (2005). All Forests Visitor Monitoring, Survey of visitors to Welsh Assembly Government woodlands 2004., p. 81. Edinburgh, UK.

UK NEA. (2011). UK National Ecosystem Assessment: Understanding Nature's Value to Society Synthesis of the Key Findings. Cambridge.

VE, (Visit England). (2014). 'Annual Survey of Visits to Visitor Attractions'. Visit England. Retrieved August 20, 2015, from <https://www.visitengland.com/biz/resources/insights-and-

statistics/research-topics/attractions-research/annual-survey-visits-visitor-attractions>

Vítek, O. (2012). 'Let's Count with geocaching'. International Conference on Monitoring and Management of Visitor Flows in Recreational and Protected Areas (MMV), pp. 228-9. Stockholm, Sweden.

de Vries, S., \& Veer, M. (2007). 'Netherland:(COST E33 WG2 Country Report), Recreation and nature tourism demand, supply and actual usage'. Sievänen T., Arnberger A., Dehez J., Grant, Jensen F. S., \& Skov-Petersen H. (eds) Forest Recreation Monitoring - A European Perspective, Working Papers of the Finnish Forest Research Institute. Helsinki.

VS, (Visit Scotland). (2013). 'Scotland Visitor Survey'. Retrieved August 20, 2015, from

<http://www.visitscotland.org/research_and_statistics/visitor_research/all_markets/scotland_visitor _survey.aspx>

VW, (Visit Wales). (2014). 'Visits to tourist attractions in Wales'. Retrieved August 20, 2015, from <http://gov.wales/statistics-and-research/visits-tourist-attractions/?lang=en>

Walls, R. L., Deck, J., Guralnick, R., Baskauf, S., Beaman, R., Blum, S., Bowers, S., et al. (2014). 'Semantics in Support of Biodiversity Knowledge Discovery: An Introduction to the Biological Collections Ontology and Related Ontologies', PLOS ONE, 9/3: e89606. DOI:

10.1371/journal.pone.0089606

Wood, S. A., Guerry, A. D., Silver, J. M., \& Lacayo, M. (2013). 'Using social media to quantify naturebased tourism and recreation', Scientific Reports, 3: 2976. DOI: 10.1038/srep02976

Xanthopoulou, E. (2007). 'Greece: (COST E33 WG2 Country Report), Recreation and nature tourism demand, supply and actual usage'. Sievänen T., Arnberger A., Dehez J., Grant, Jensen F. S., \& SkovPetersen H. (eds) Forest Recreation Monitoring - A European Perspective, Working Papers of the Finnish Forest Research Institute. Helsinki.

Zandersen, M., \& Tol, R. S. J. (2009). 'A meta-analysis of forest recreation values in Europe', Journal of Forest Economics, 15/1-2: 109-30. DOI: 10.1016/j.jfe.2008.03.006 


\section{Appendix}

Table A3.1: Database of annual visitor counts to sampled nature areas

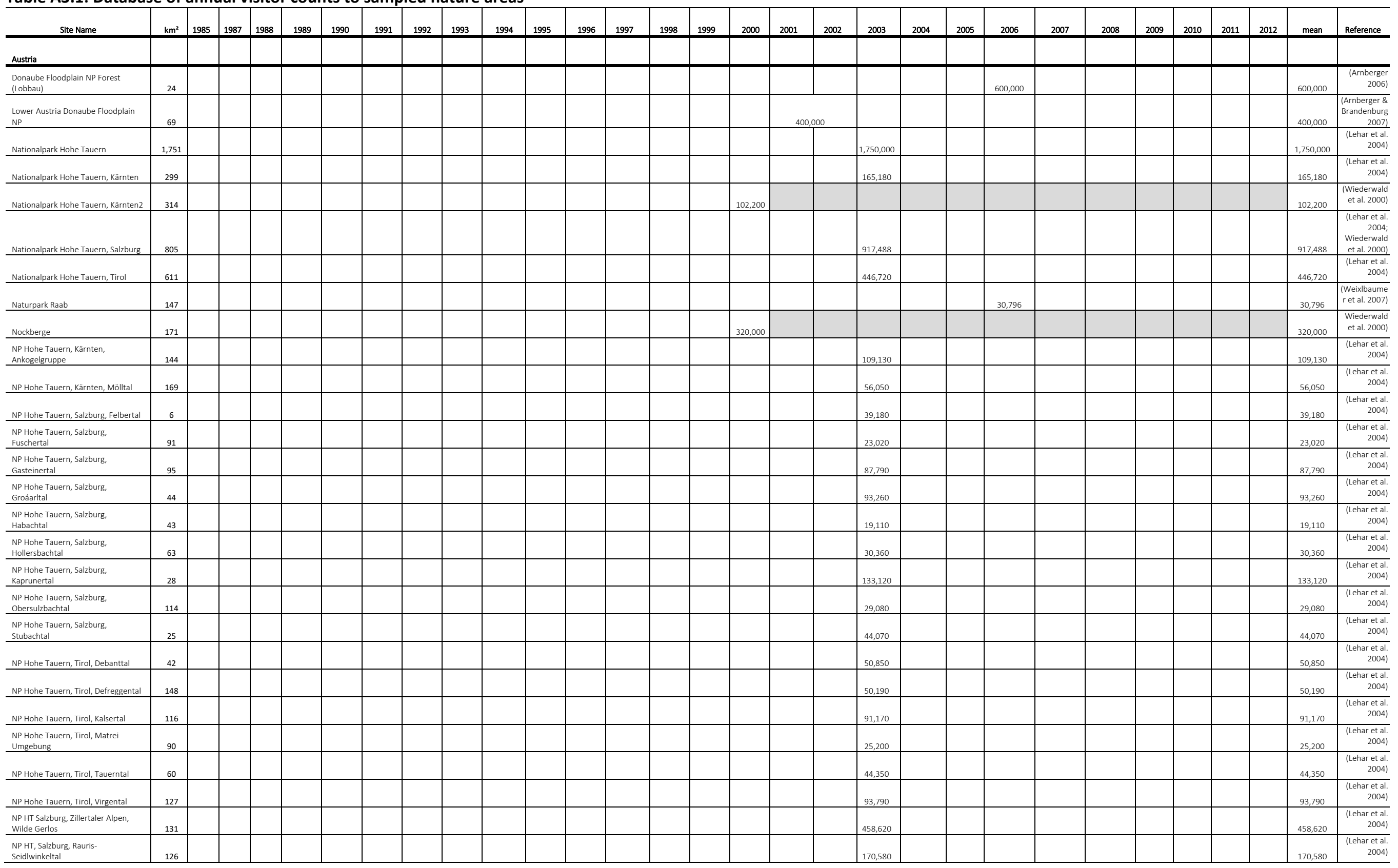




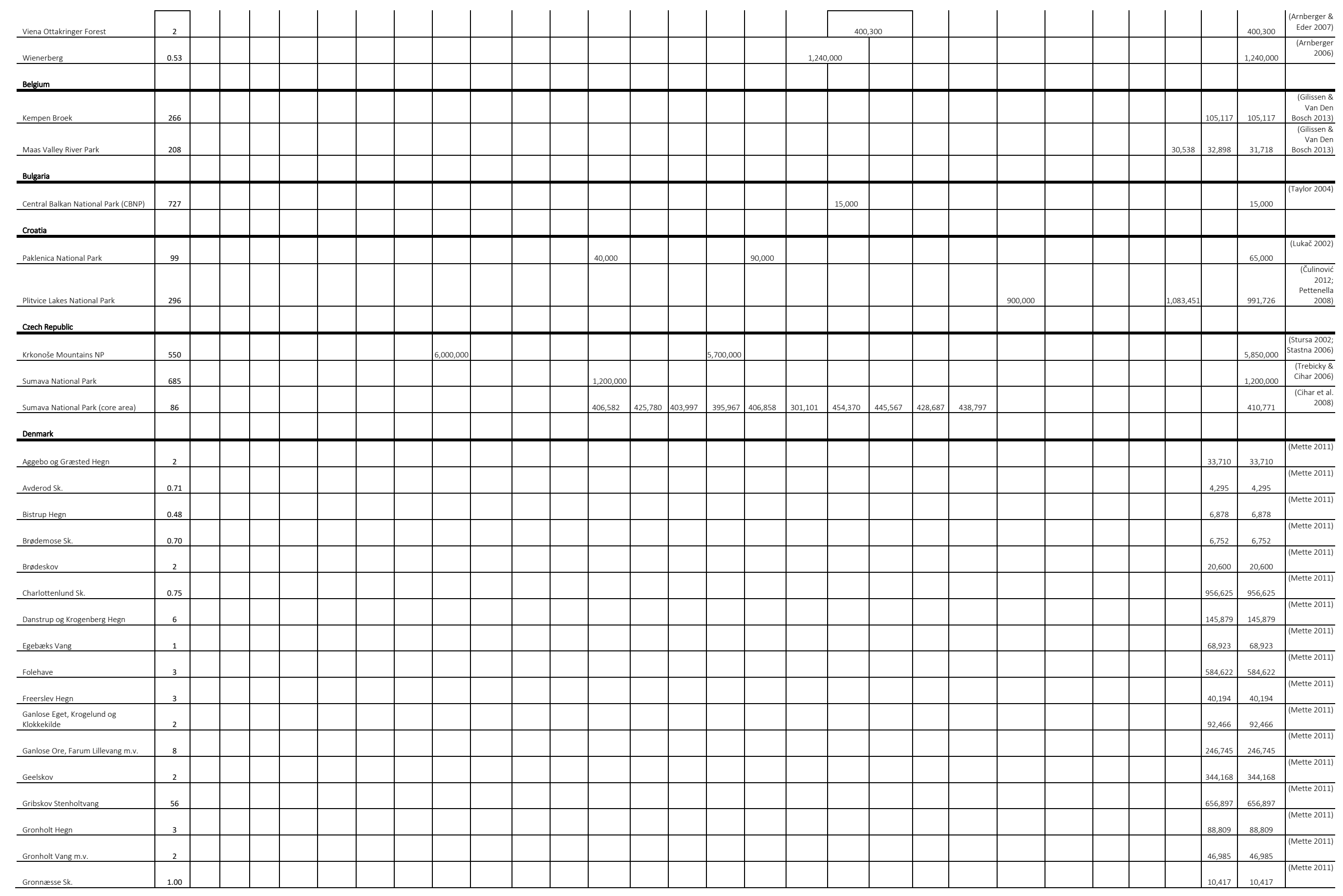




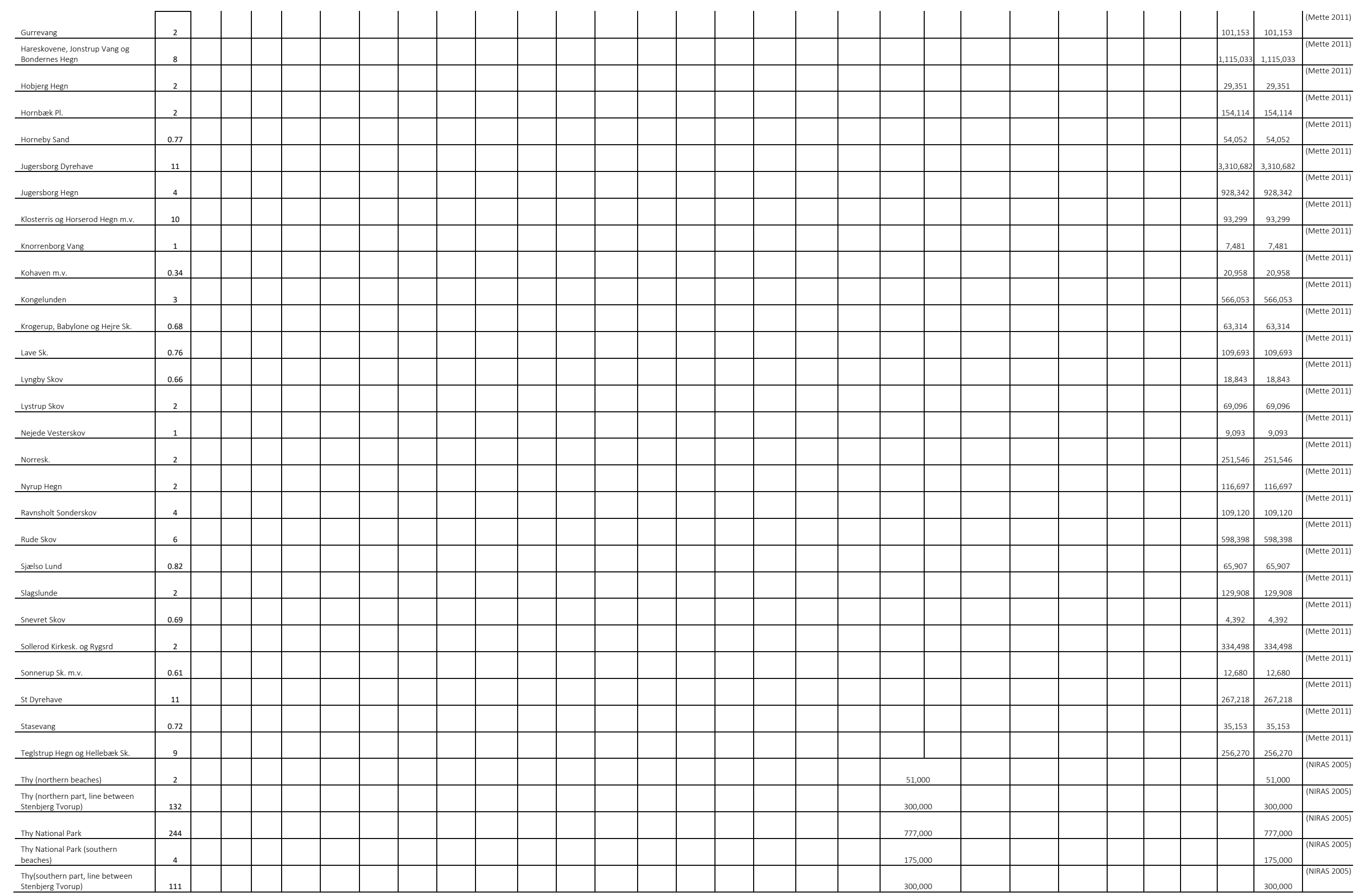




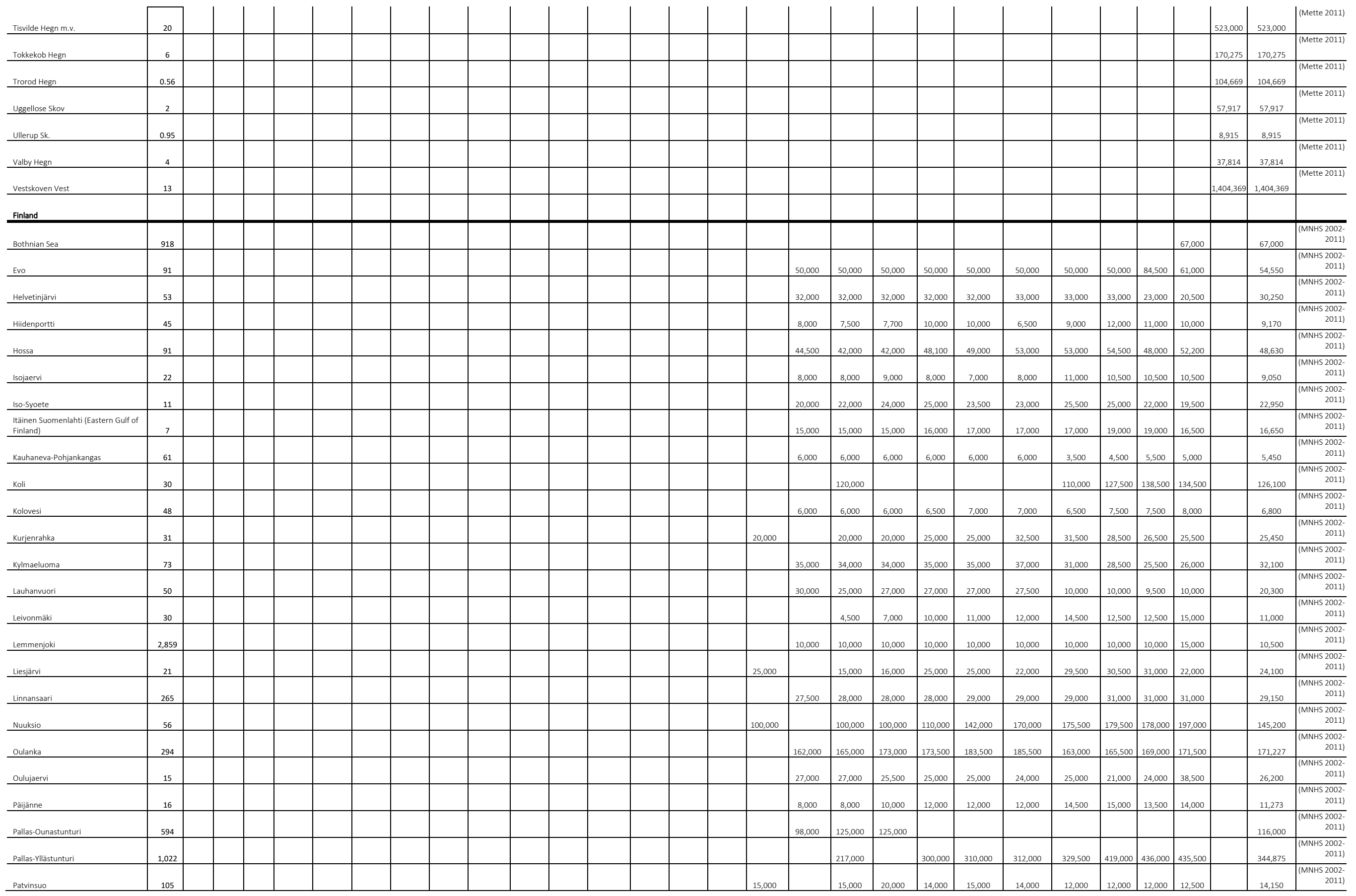




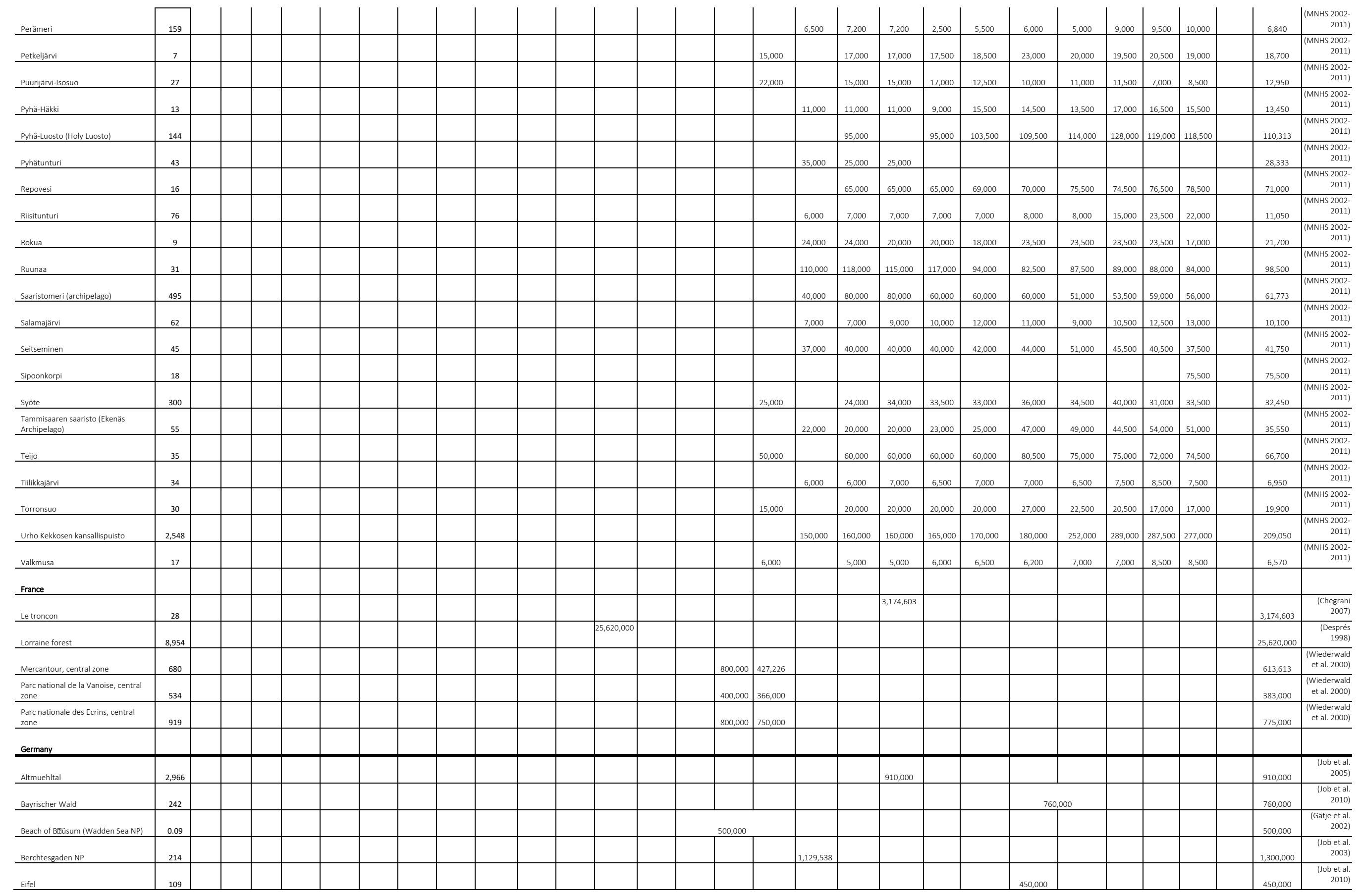




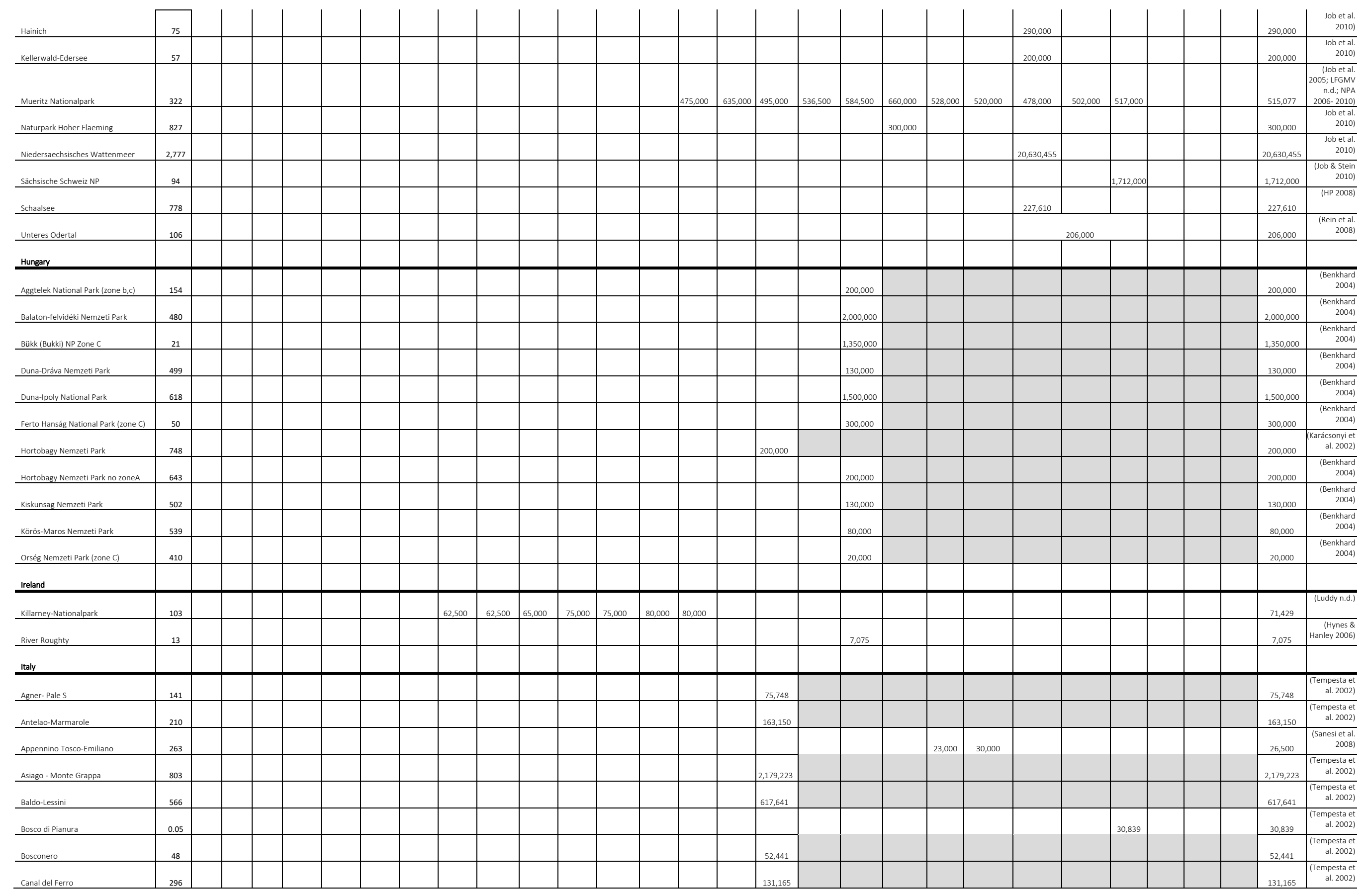




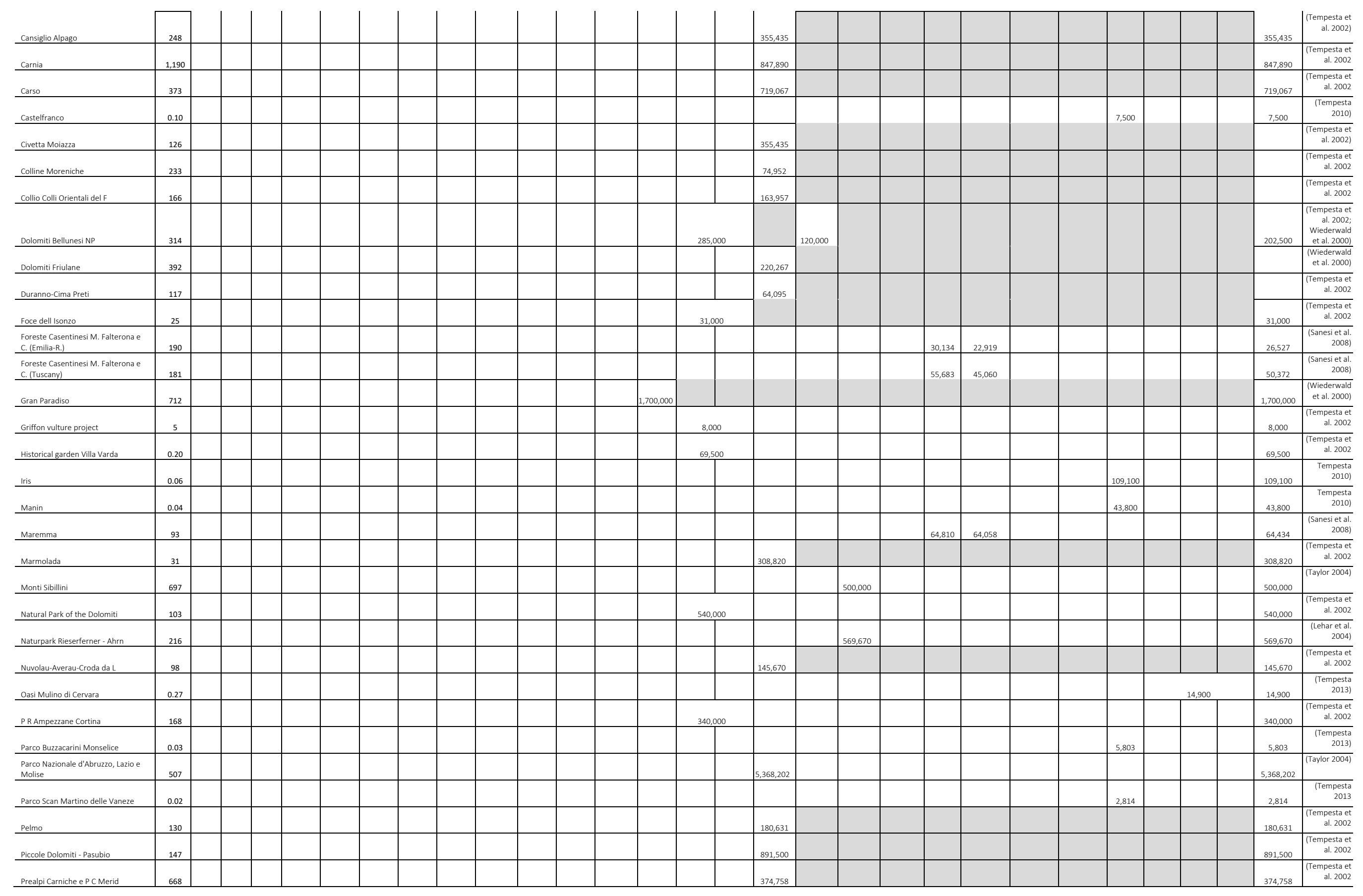




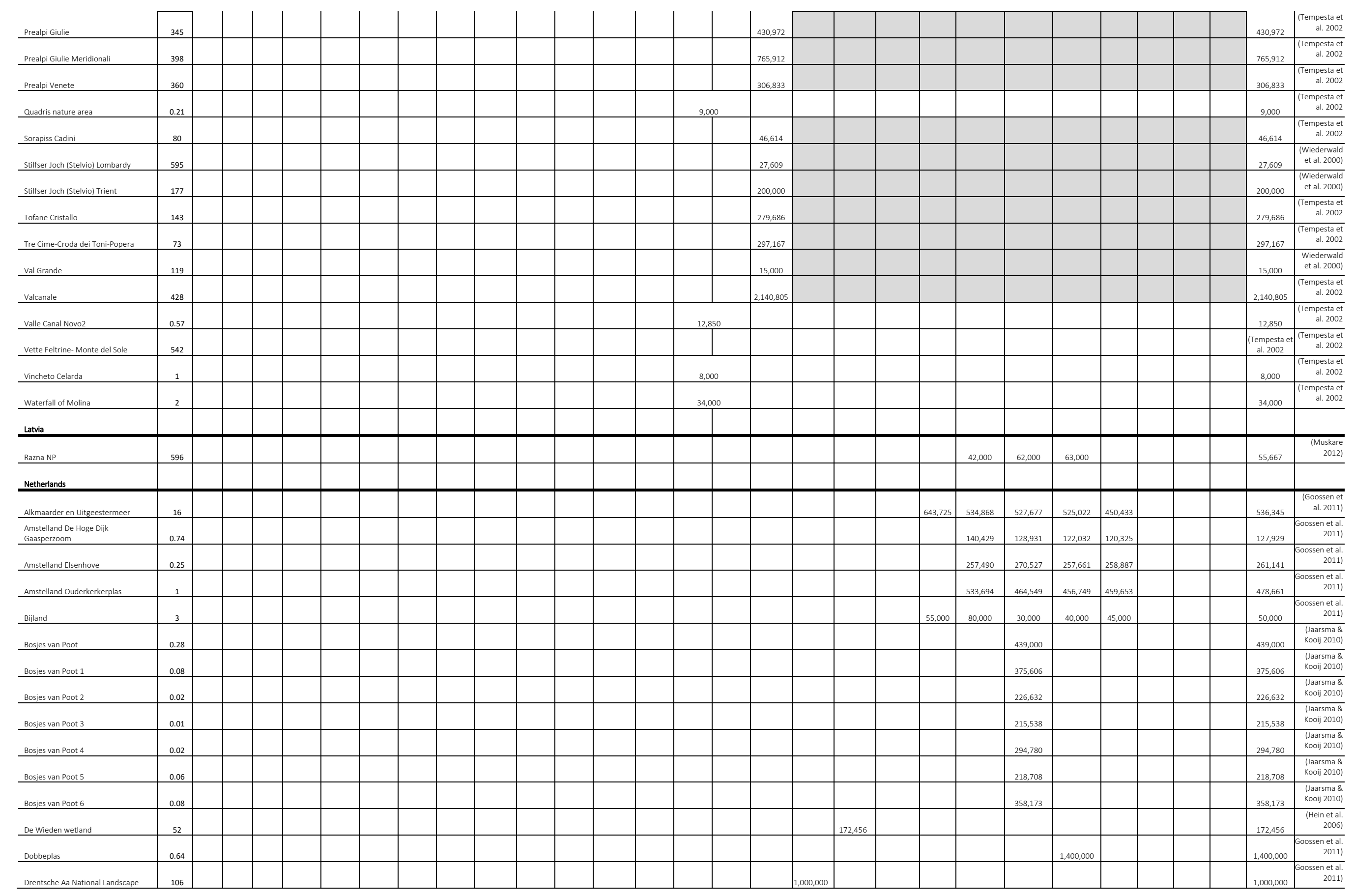




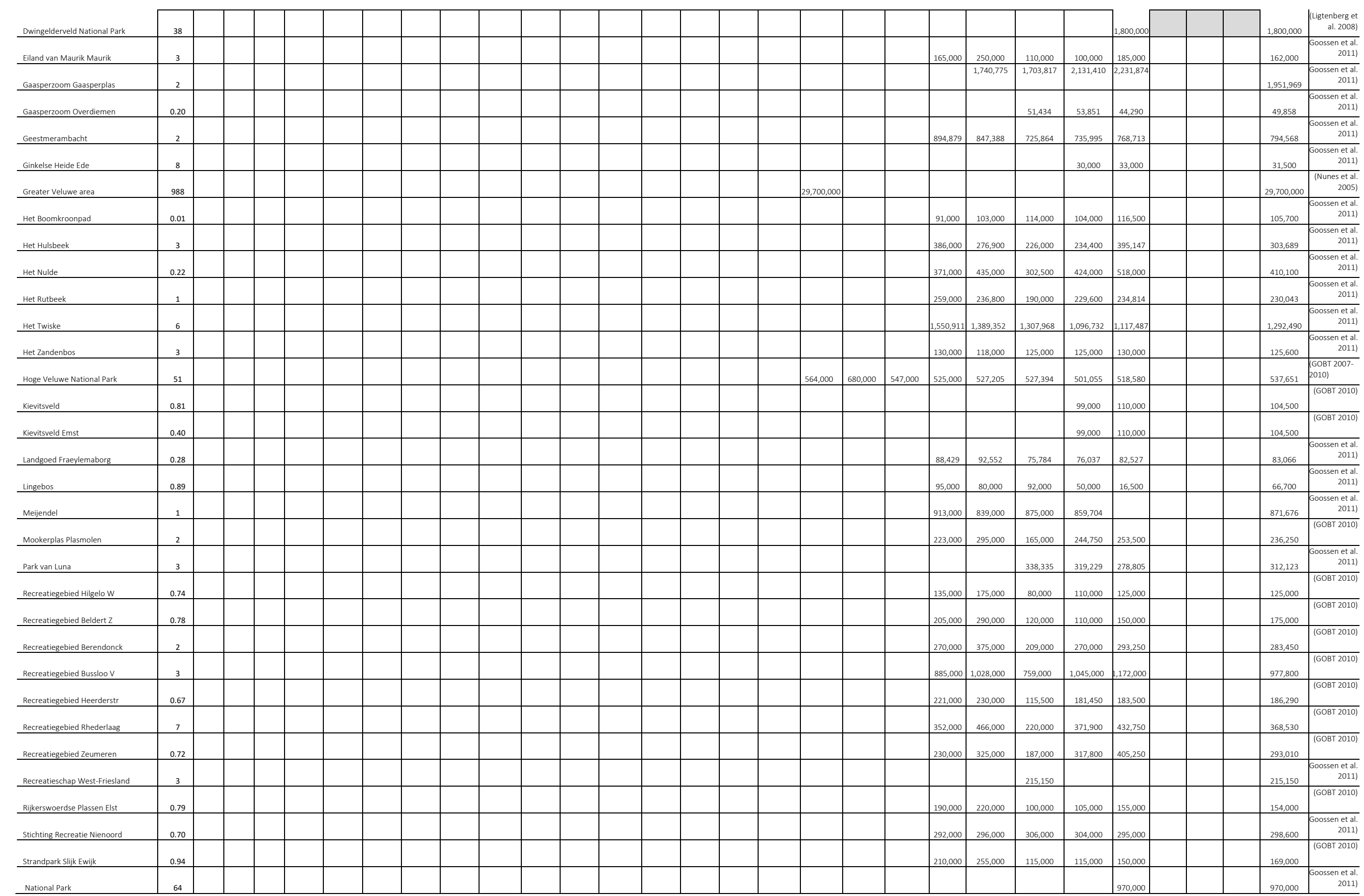




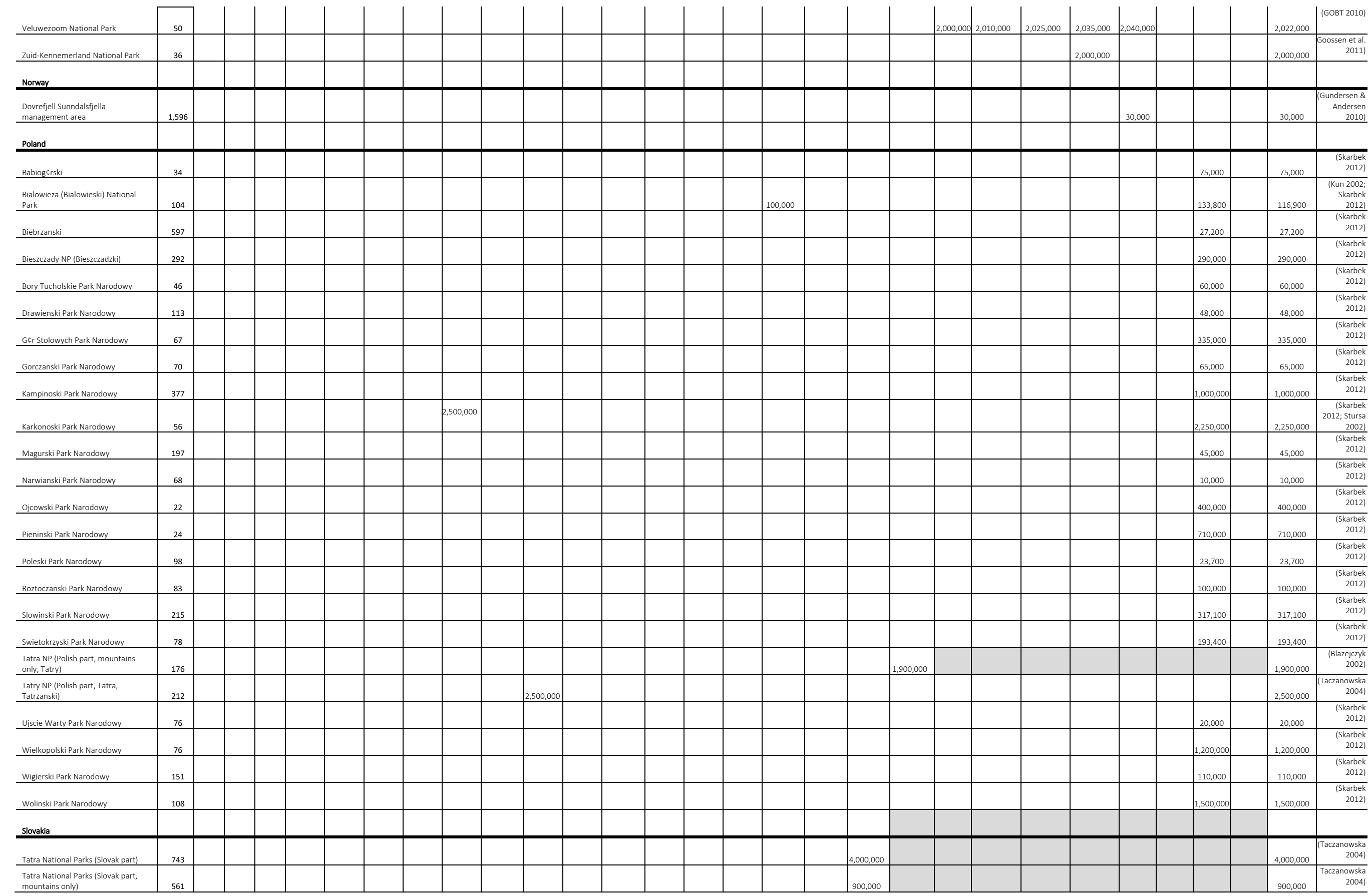




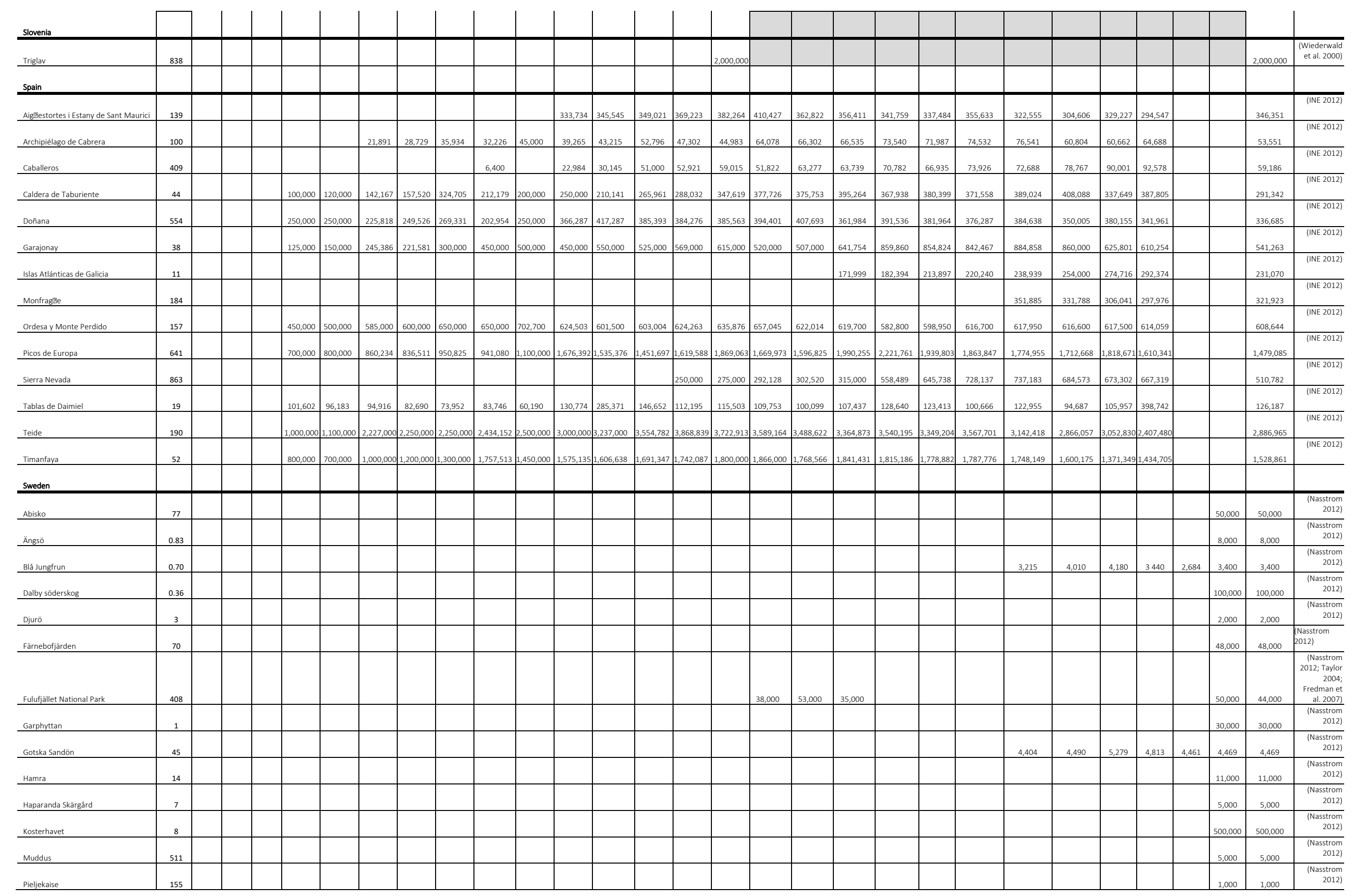




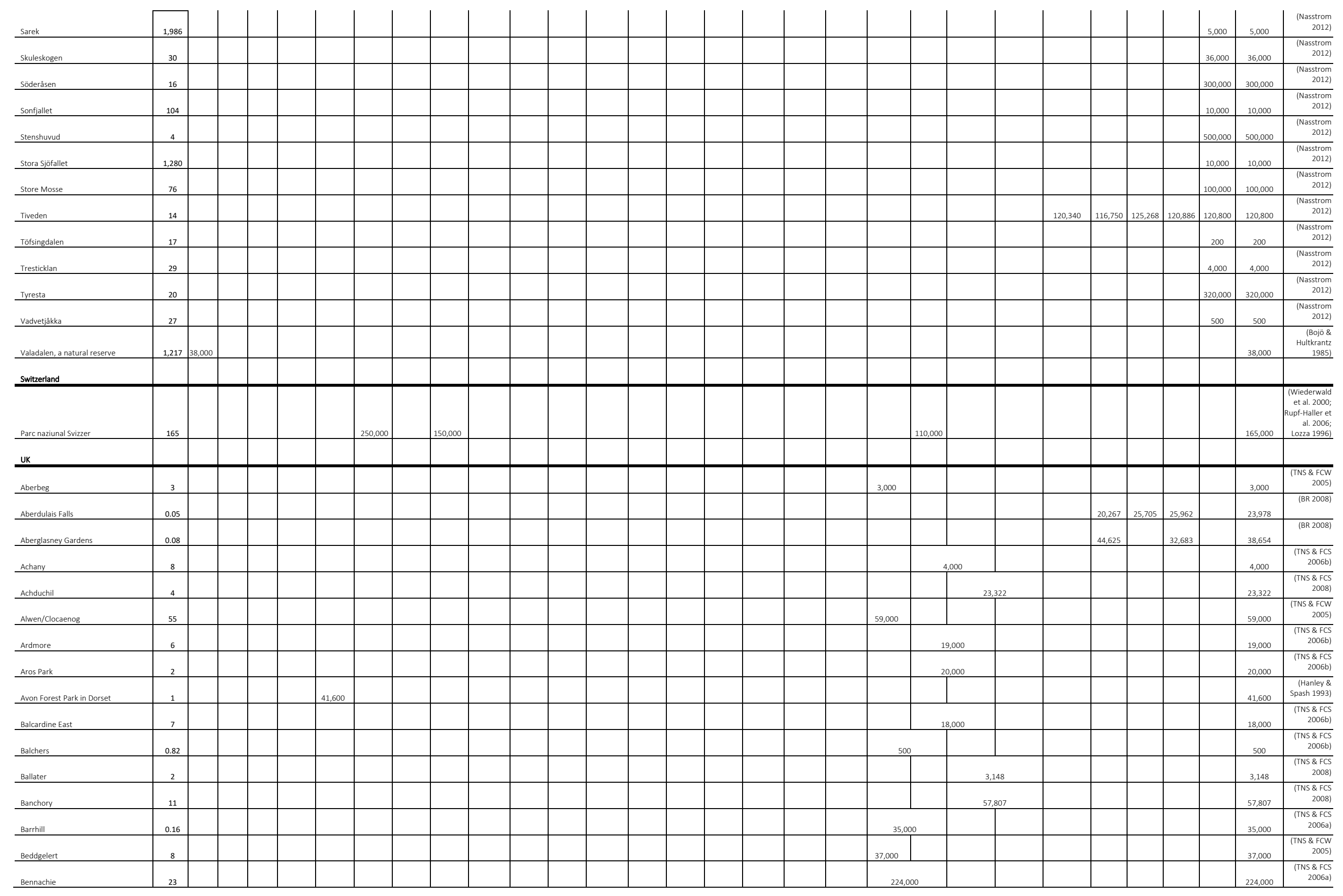




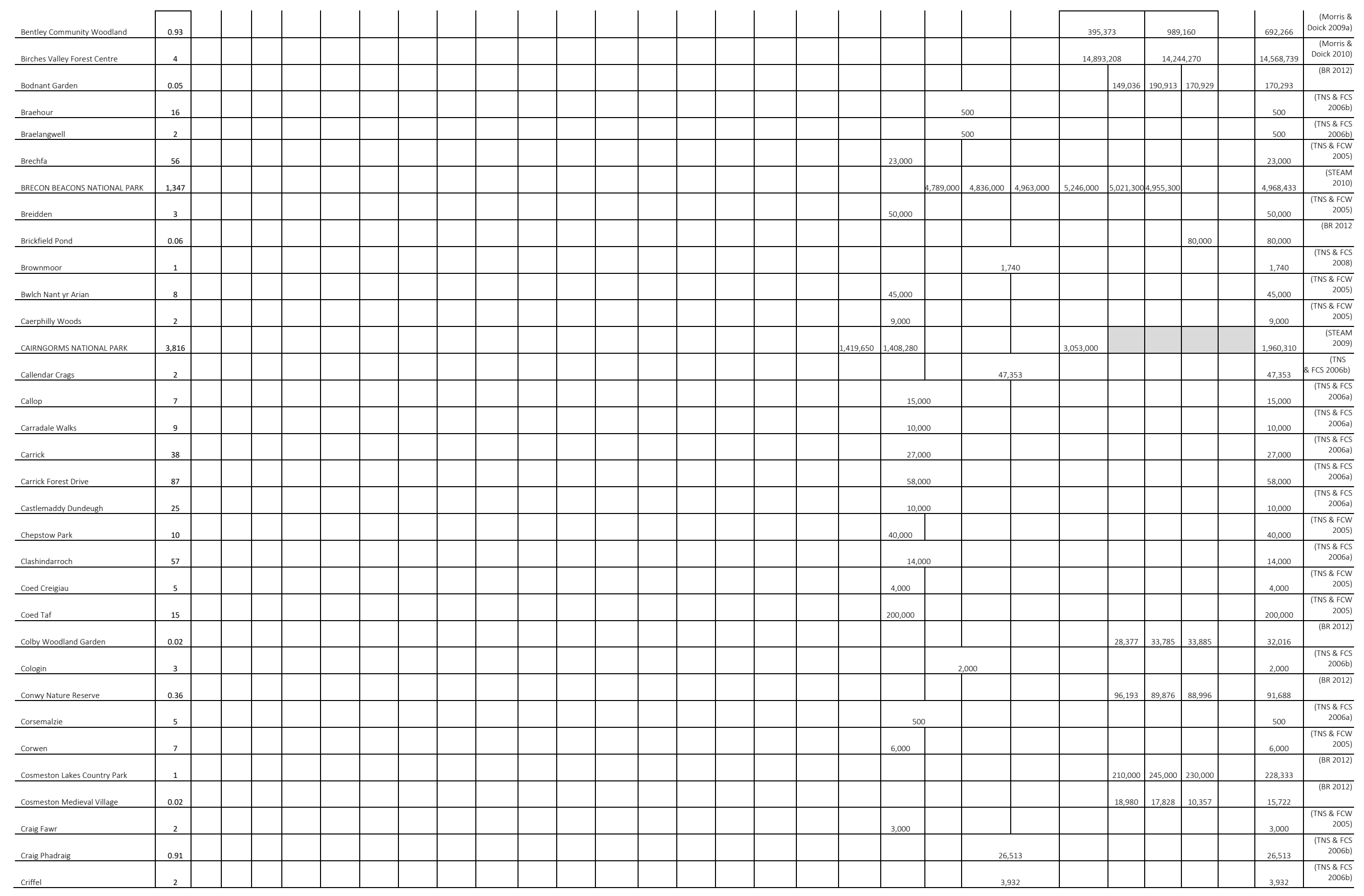




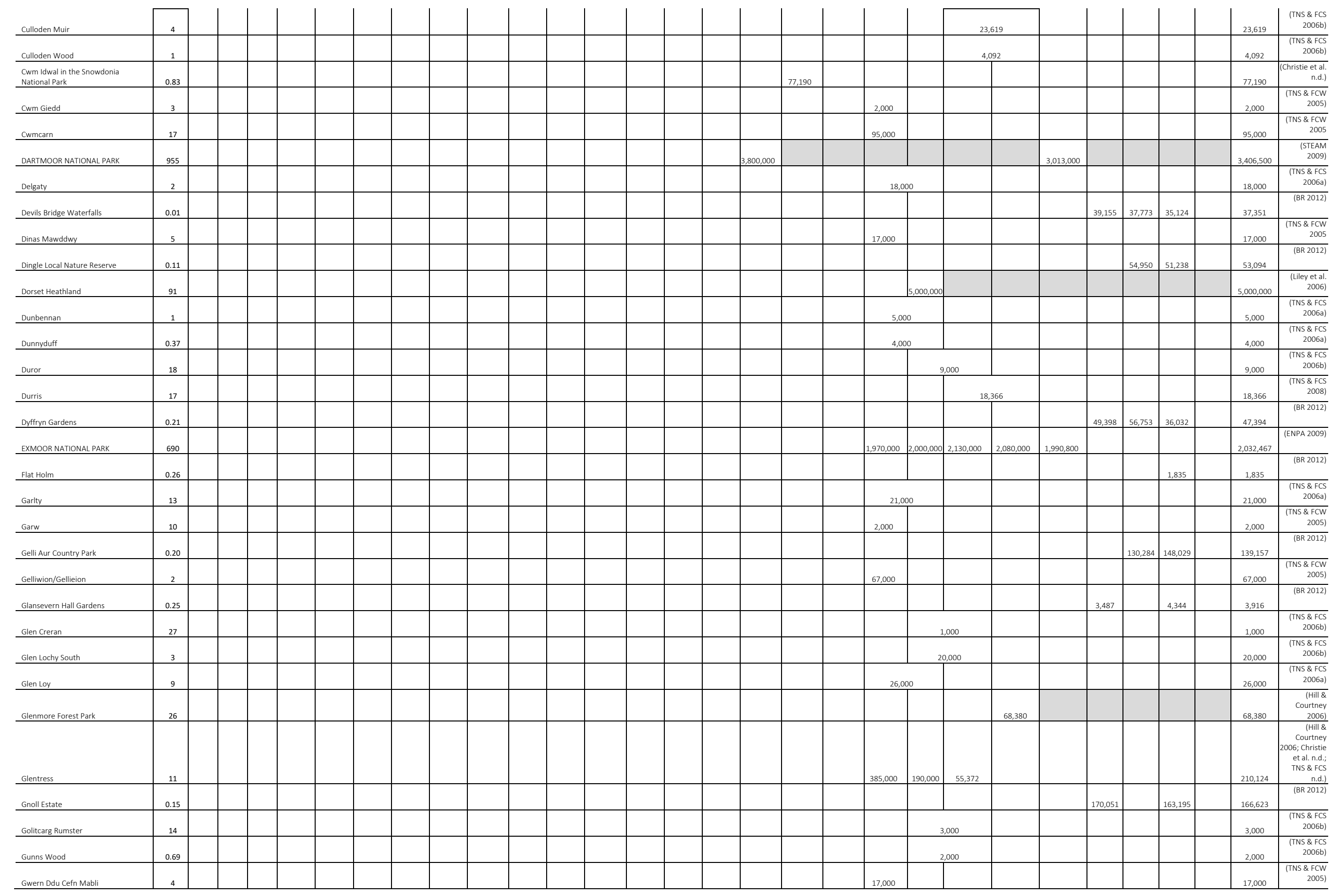




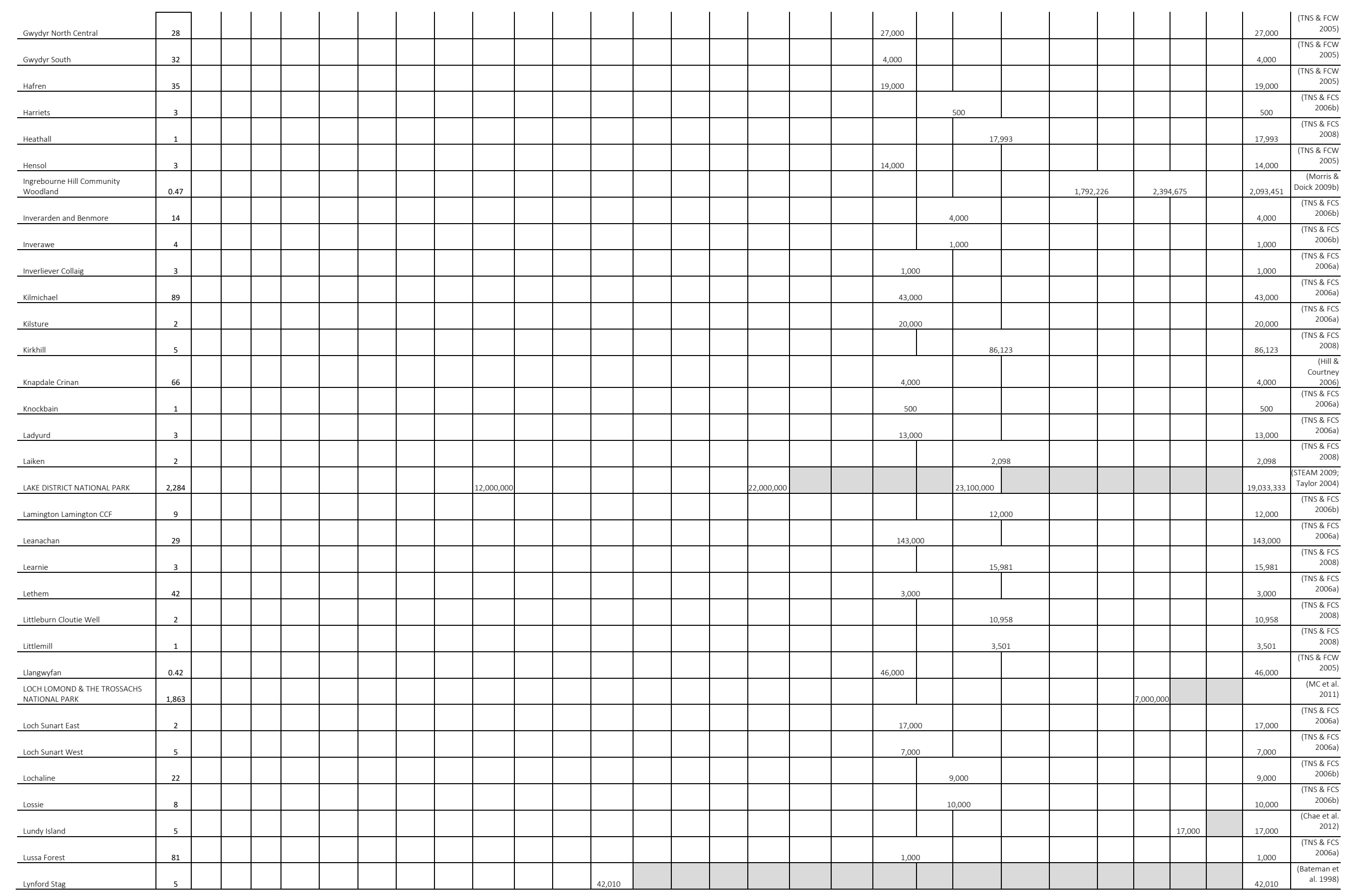




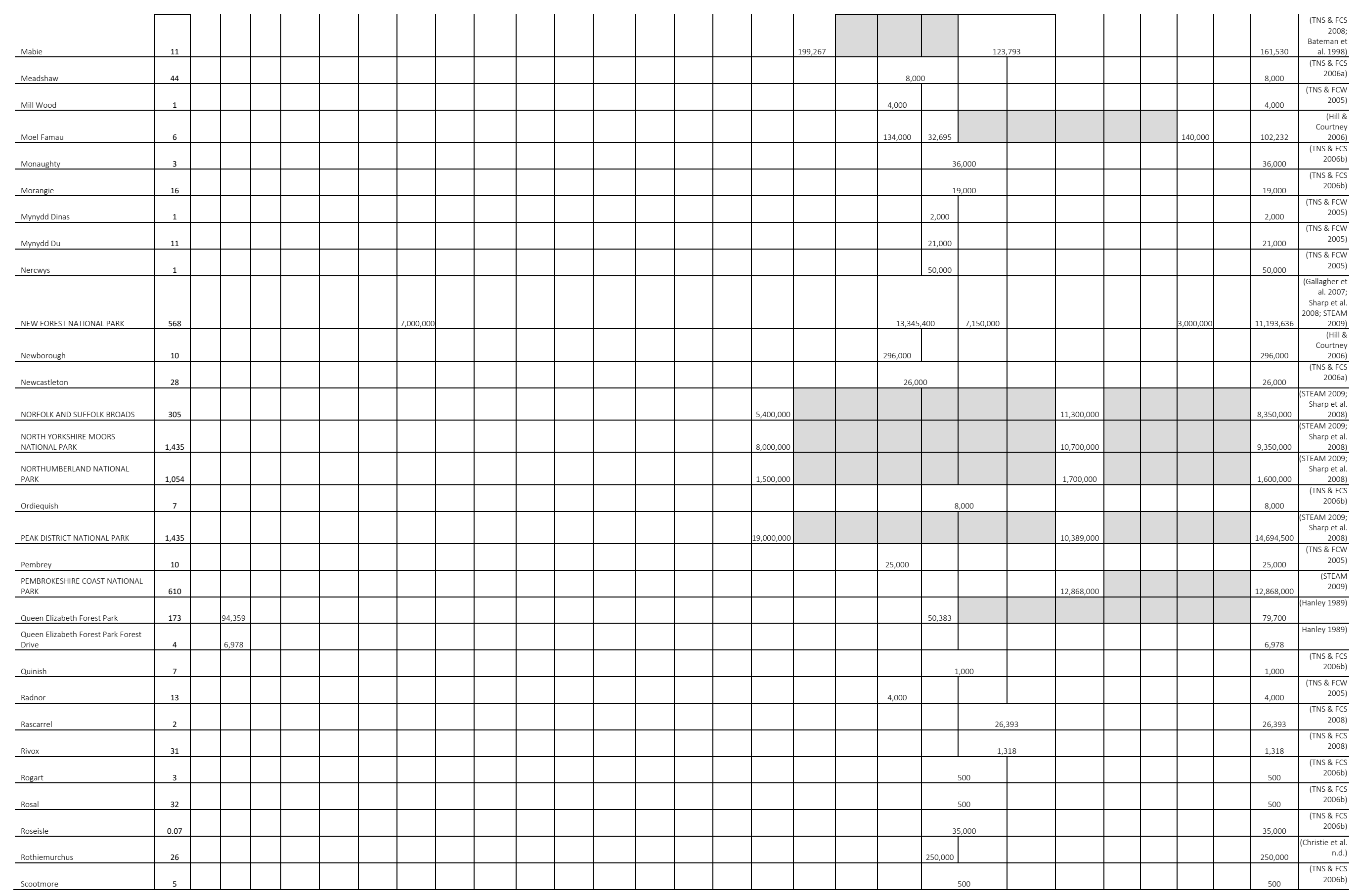




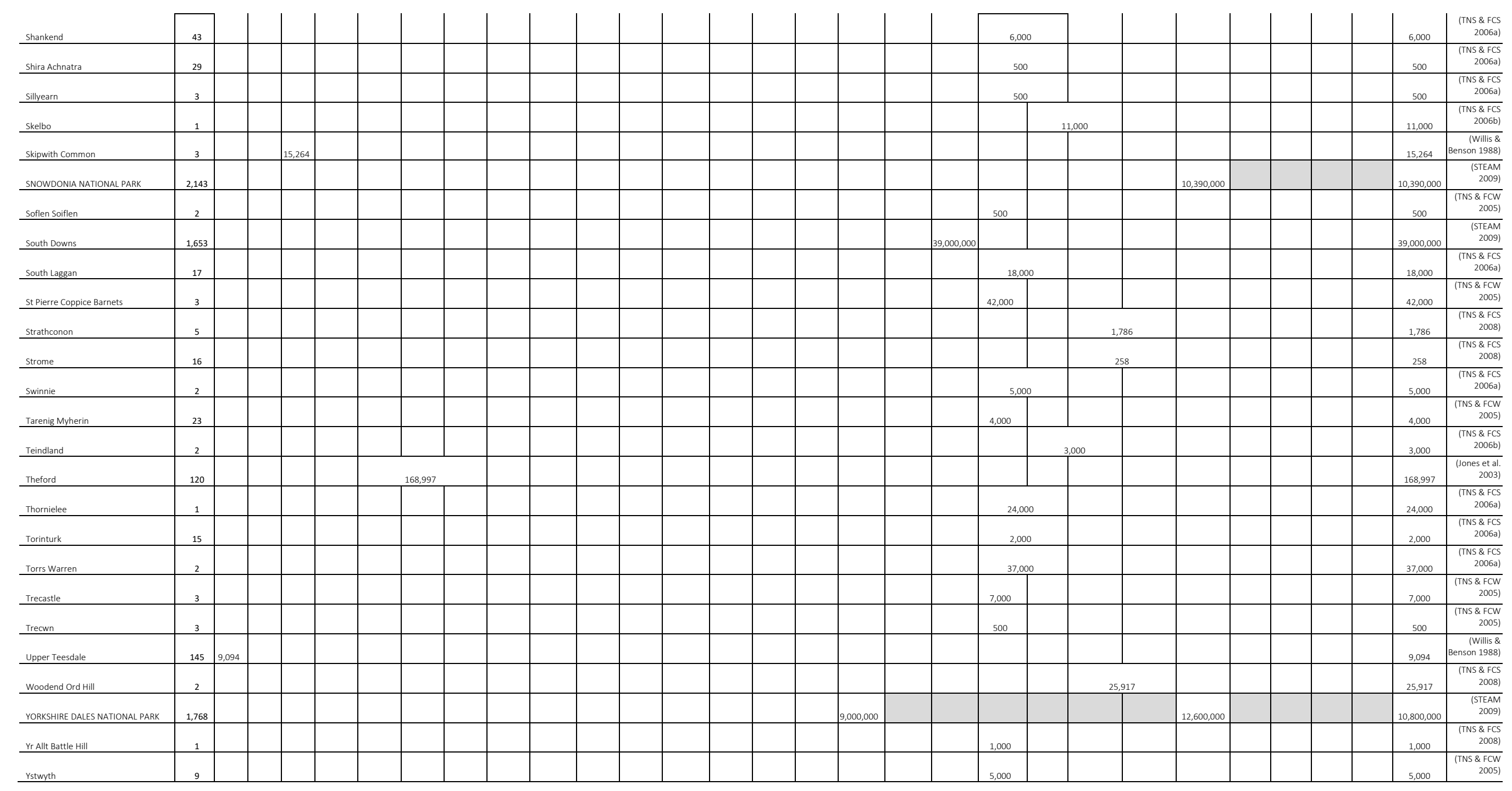

